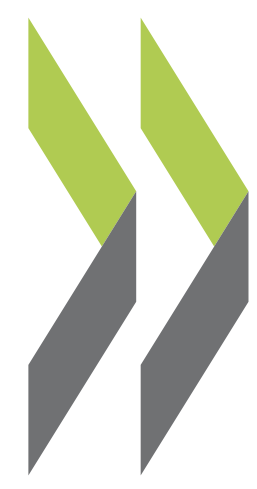

OECD Economics Department Working Papers No. 991

Tertiary Education: Developing Skills for Innovation and LongTerm Growth in Canada

\section{Calista Cheung, \\ Yvan Guillemette,} Shahrzad Mobasher-Fard 
Organisation de Coopération et de Développement Économiques

Organisation for Economic Co-operation and Development

20-Sep-2012

ECONOMICS DEPARTMENT

English - Or. English

\section{TERTIARY EDUCATION: DEVELOPING SKILLS FOR INNOVATION AND LONG-TERM GROWTH IN CANADA}

ECONOMICS DEPARTMENT WORKING PAPERS No. 991

By Calista Cheung, Yvan Guillemette and Shahrzad Mobasher-Fard

All OECD Economic Department Working Papers are available through OECD's Internet website at http://www.oecd.org/eco/Workingpapers

JT03326583

Complete document available on OLIS in its original format

This document and any map included herein are without prejudice to the status of or sovereignty over any territory, to the delimitation of international frontiers and boundaries and to the name of any territory, city or area. 


\section{ABSTRACT/RESUME}

\section{Tertiary education: developing skills for innovation and long-term growth in Canada}

The tertiary education system in Canada performs well in fostering a skilled workforce with generally good labour-market outcomes and is internationally recognised for its research contributions. Tertiary educational attainment is high, but participation rates will need to continue expanding to maintain the supply of highly skilled labour as the population ages and the needs of the knowledge-based economy rapidly evolve. This should be achieved by encouraging access to higher education for disadvantaged socio-economic groups, while enhancing the flexibility of the system to allow students with diverse needs to move between institutions more easily to meet their learning objectives. Immigration is another important source of skills that could be better utilised. The development of skills for innovation can be improved by increasing the integration of technical, business and communications skills training with practical industry experience within tertiary education programmes. In an environment of government spending restraint, the quality of tertiary education could be strengthened by increasing the distinction between institutions that target research and those that emphasise teaching and re-evaluating tuition policies in provinces where public finances are stretched. This Working Paper relates to the 2012 OECD Economic Review of Canada (www.oecd.org/eco/surveys/Caanada).

\section{JEL classification codes: I22; I25; I28}

Keywords: tertiary education; participation rate; graduation rate; attainment rate; access; access to tertiary education; foreign tertiary students; grants; scholarships; student loans; tuition fees; tuition tax credits

$* * * * * * *$

\section{Enseignement supérieur : développer les compétences au service de l'innovation et de la croissance à long terme en Canada}

Le système d'enseignement supérieur canadien permet d'avoir une main-d'œuvre qualifiée, qui obtient globalement de bons résultats sur le plan professionnel. Il est par ailleurs reconnu à l'échelle mondiale pour ses contributions à la recherche. Les taux de réussite dans le supérieur sont élevés, mais le taux de fréquentation va devoir s'améliorer si l'on veut maintenir l'offre de main-d'œuvre qualifiée, à mesure que la population vieillit et que les besoins de l'économie du savoir évoluent. Il faudrait pour cela favoriser l'accès à l'enseignement supérieur des catégories défavorisées, tout en renforçant la flexibilité du système afin de permettre à des étudiants ayant différents besoins de changer d'établissement plus facilement pour atteindre leurs objectifs d'apprentissage. L'immigration constitue également une source précieuse de compétences, qui pourrait être mieux utilisée. Le développement des compétences au service de l'innovation peut être amélioré en associant davantage les compétences techniques, commerciales et de communication à l'expérience pratique dans le cadre des programmes d'enseignement supérieur. Dans un contexte de rigueur budgétaire, la qualité de l'enseignement supérieur pourrait être renforcée en faisant une plus grande distinction entre les établissements qui privilégient la recherche et ceux qui mettent l'accent sur l'enseignement, et en réévaluant les politiques en matière de droits d'inscription dans les provinces où les finances publiques sont tendues. Ce Document de travail se rapporte à l'Étude économique de l'OCDE du Canada 2012 (www.oecd.org/eco/etudes/Canada).

\section{Classification JEL : I22; I25; I28}

Mots clefs : éducation supérieure ; taux de participation ; taux de graduation ; taux de réussite ; accès à l'éducation supérieure ; étudiants étrangers ; subventions ; bourses ; prêts étudiants ; frais de scolarité ; crédits d'impôt pour frais de scolarité

\section{(C) OECD (2012)}

You can copy, download or print OECD content for your own use, and you can include excerpts from OECD publications, databases and multimedia products in your own documents, presentations, blogs, websites and teaching materials, provided that suitable acknowledgment of OECD as source and copyright owner is given. All requests for commercial use and translation rights should be submitted to rights@oecd.org. 


\section{Table of contents}

Tertiary education: developing skills for innovation and long-term growth in Canada ...................... 5

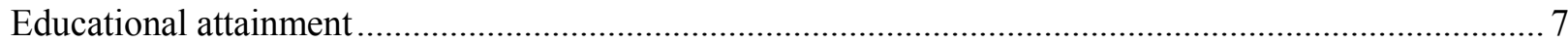

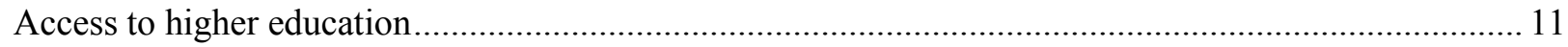

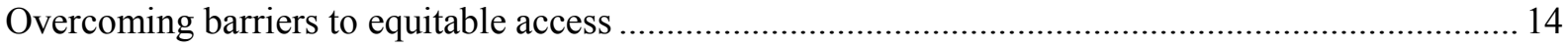

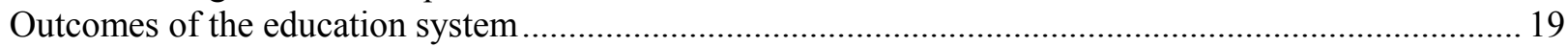

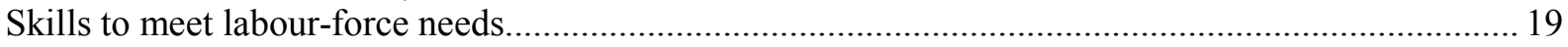

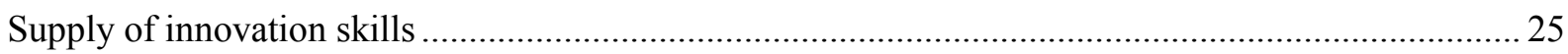

The higher education system: aligning institutional incentives with policy priorities ............................ 27

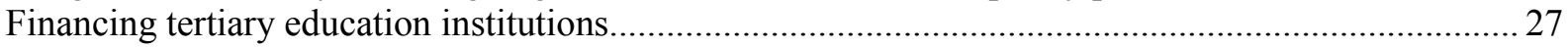

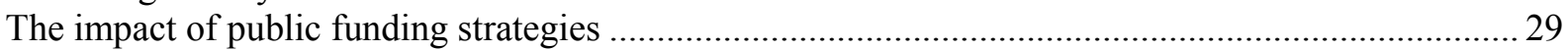

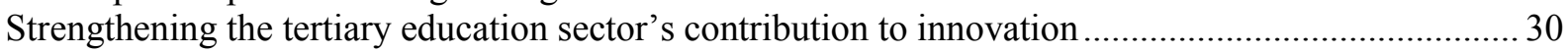

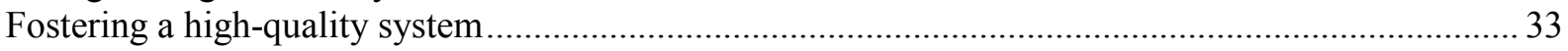

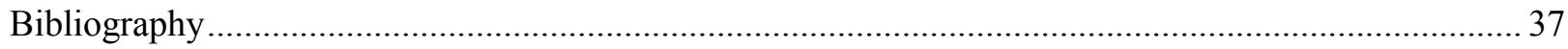

\section{Boxes}

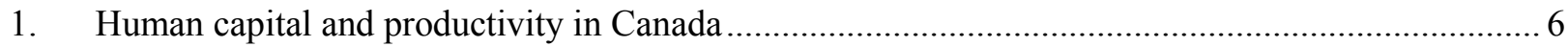

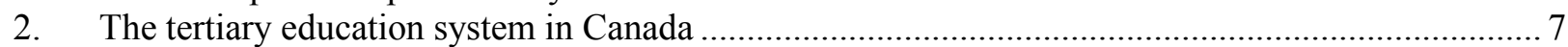

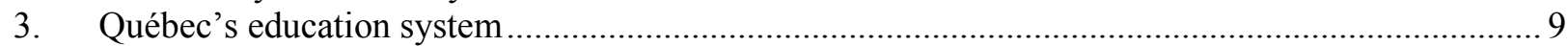

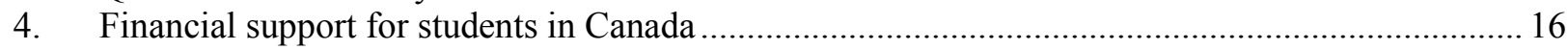

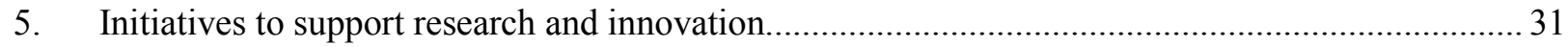

6. The quality-assurance framework for higher education in Canada.............................................. 32

7. Policy recommendations for improving tertiary education ........................................................ 37

\section{Tables}

1. Employment of tertiary graduates by skill level …............................................................. 21

A.1. Average labour productivity by province and industry, 1997-2010 …..................................... 43

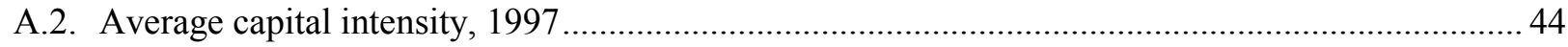

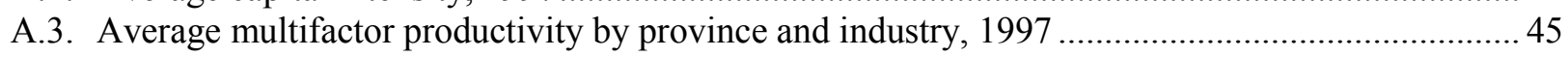

A.4. Estimated provincial MFP gaps relative to Ontario .................................................................... 46

\section{Figures}

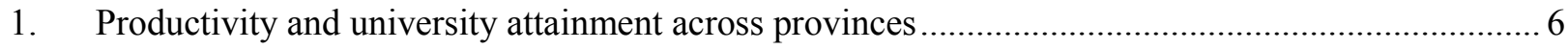

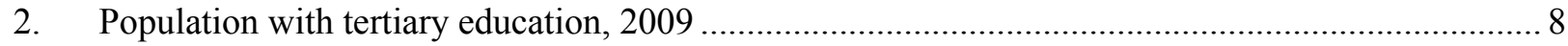

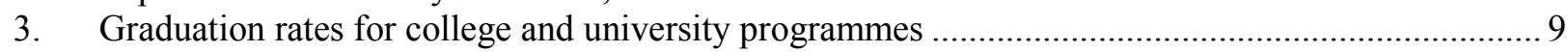

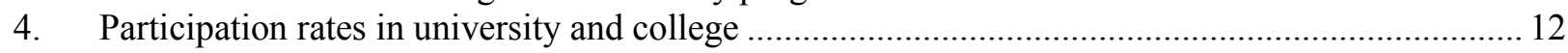

5. Post-secondary participation rates by parental education .......................................................... 13

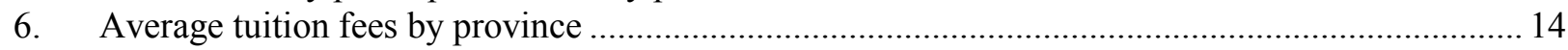

7. Average annual university tuition fees for full-time students .................................................. 15

8. Public subsidies for education to private entities for tertiary education ....................................... 18

9. Relative earnings of 25-64 year-olds with tertiary education, 2009 ........................................... 20 


\section{$\mathrm{ECO} / \mathrm{WKP}(2012) 68$}

10. Earnings premium and employment rate relative to high school graduates................................. 20

11. Earnings distribution of 25-64 year-olds with university education ............................................22

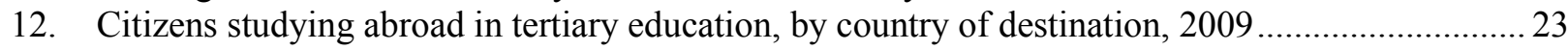

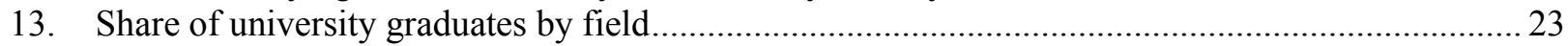

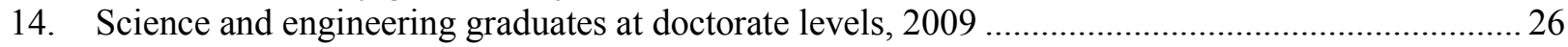

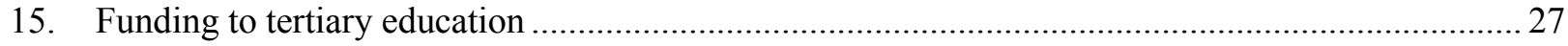

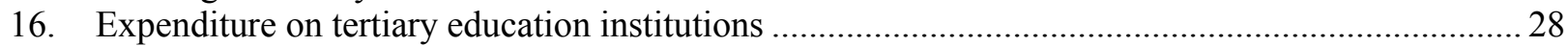

17. Ratio of university full-time students to full-time teaching staff ................................................... 33

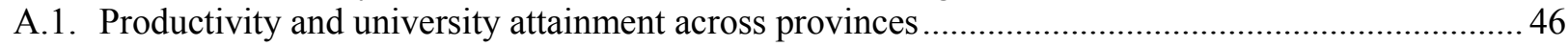

The statistical data for Israel are supplied by and under the responsibility of the relevant Israeli authorities. The use of such data by the OECD is without prejudice to the status of the Golan Heights, East Jerusalem and Israeli settlements in the West Bank under the terms of international law. 


\title{
Tertiary education: developing skills for innovation and long-term growth in Canada
}

\author{
By \\ Calista Cheung, Yvan Guillemette and Shahrzad Mobasher-Fard ${ }^{1}$
}

\begin{abstract}
As economic activity in Canada becomes increasingly knowledge-based, human capital provides the foundation for innovation and gains in productivity and plays a critical role in raising living standards over the longer term. Education can lift the quality of labour and raise economic performance through its effects on the pace of technological change, the adoption of more innovative and productive work practices, labour-market participation and managerial quality. Education can also contribute to equality of opportunity and promote broader benefits through lower crime, improved health outcomes and greater social cohesion. However, higher skill levels can translate into greater economic prosperity only if individuals are able to employ those skills productively. Canadian policymakers thus face the key challenge of producing the right mix of skills to meet both present and future labour-force needs and to support innovation-driven growth.
\end{abstract}

Canada already enjoys a comparatively high level of educational attainment. High-school completion is nearly universal, and international student assessment results indicate that the elementary and lower secondary education system graduates students with strong performance by global standards. In reading, maths and science, Canadian students perform at or above the OECD average PISA scores in almost all provinces. Although these outcomes vary across socio-economic groups, the disparities are small compared to other OECD countries, suggesting a relatively equitable compulsory education system (OECD, 2010a). The country also benefits from high attainment rates at the tertiary level (Box 1).

All of these outcomes indicate a highly skilled talent base to support strong productivity growth (Box 2). Nonetheless, Canada has not enjoyed rapid productivity gains for many years. Also, it lags somewhat in the development of computer science, and business and advanced skills. These deficiencies are a concern as the challenges posed by globalisation and demographic ageing highlight the need to raise educational attainment and quality, and to continuously upgrade these skills through lifelong learning to remain internationally competitive and avoid future skills shortages. This paper assesses the record of the tertiary education system in delivering the appropriate mix of skills to sustain growth in a knowledge-based economy driven by continuous innovation. The tertiary sector here refers to education offered at both universities and colleges (tertiary education institutions or TEIs), and for the purposes of this paper the term "college" will refer to both community colleges and polytechnics (see Box 2).

1. Ms. Cheung and Mr. Guillemette are Economists, and Ms. Mobasher-Fard formerly a Consultant, in the OECD Economics Department. This paper was originally produced for the OECD Economic Survey of Canada published in June 2012 under the authority of the Economic and Development Review Committee. The authors thank Noel Baldwin, Alexandra Bibbee, Andrew Dean, Robert Ford, Peter Jarrett, Andrew Parkin, Deborah Roseveare, Carolina Torres, Richard Yelland and Canadian government officials for their constructive comments on earlier versions of this paper. The authors also thank Françoise Correia and Mee-Lan Frank for excellent research assistance and technical preparation. 


\section{Box 1. Human capital and productivity in Canada}

Economic theory predicts that in a small open economy with perfect capital mobility, human capital is complementary to physical capital in the production process (Barro et al., 1995). Because of the impossibility of using human capital as collateral, financing constraints on investments in education prevent the instantaneous flow of financial capital to where rates of return are highest. It is thus human capital accumulation that ultimately determines the rate of return on physical capital and divergences in per capita income levels. The relationship between human capital and income per capita can be tested on data for Canadian provinces where social infrastructure is fairly similar, to better understand regional disparities in standards of living. Indeed, Coulombe and Tremblay (2007) find strong evidence that differences in literacy levels and university attainment play a significant role in explaining relative per capita income levels across Canadian provinces.

Industry composition differs widely across the country and may explain a considerable portion of the regional variation observed in productivity. Everything else equal, provinces with a large share of output coming from high-productivity industries will tend to have higher overall productivity levels. It is therefore important to account for such differences in sectoral makeup when assessing the relationship between human capital and output across different regions. This can be done by using disaggregated data on real output for 18 industries and 10 provinces over the 1997-2010 period. Multifactor productivity levels can be derived by industry and province from the residuals of conventional Cobb-Douglas production functions (see Annex for details on methodology and data). After controlling for industry composition and cyclical economic effects, differences in productivity levels across provinces appear to be strongly correlated with educational attainment, as measured by the population share with a university degree (Figure 1).

Figure 1. Productivity and university attainment across provinces

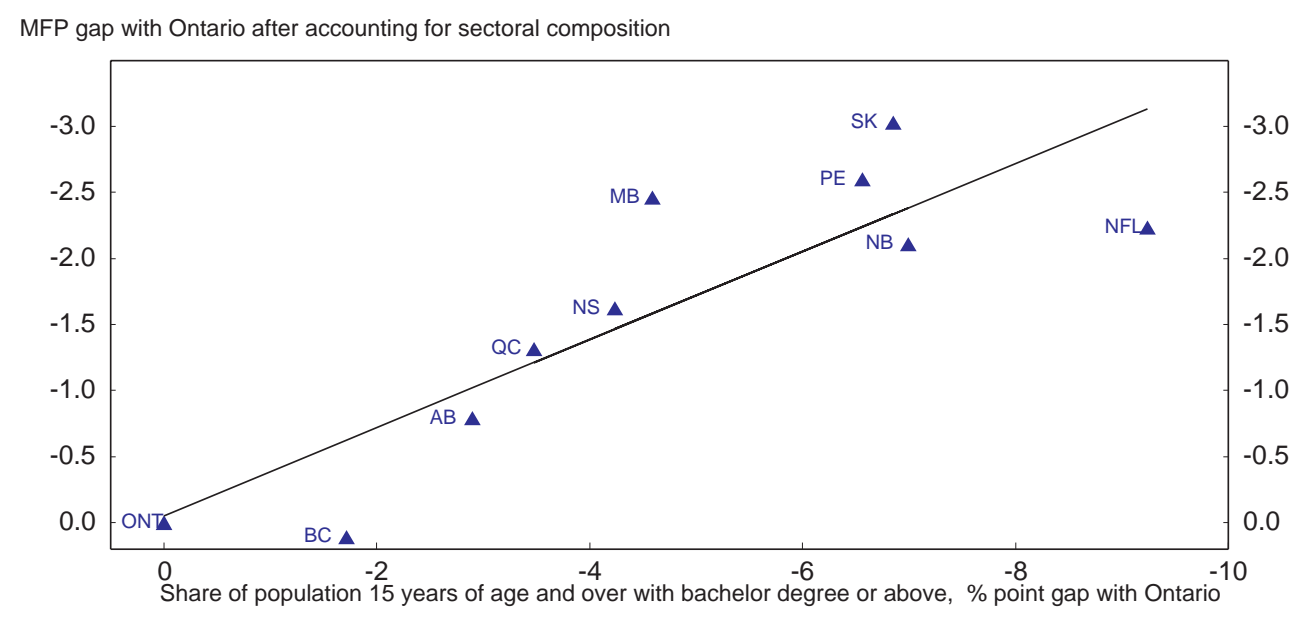

Source: OECD calculations based on Statistics Canada, CANSIM tables 031-0002, 379-0025 and 383-0009. See Annex. 


\section{Box 2. The tertiary education system in Canada}

Tertiary education is normally defined using the International Standard Classification of Education (ISCED) to include programme levels 5A, 5B and 6 . Tertiary-type 5A refers largely to theory-based programmes lasting at least three years full-time, and typically covers university undergraduate and master's degrees providing qualification for entry into advanced research programmes such as PhDs (tertiary-type 6) as well as high-skill professions (e.g. medicine, dentistry, law). Tertiary-type 5B programmes are shorter in duration and focus on practical, technical or occupational skills for direct entry into the labour market. Level ISCED 4 programmes include occupational preparation and adult education programmes and are labelled non-tertiary post-secondary education and may be provided by either upper-secondary or post-secondary education institutions, depending on the country.

Tertiary education institutions (TEls) in Canada generally include universities, community colleges, polytechnics and university-colleges. Universities normally offer tertiary-type $5 \mathrm{~A}$ and 6 programmes, whereas colleges traditionally provide tertiary type-5B programmes. Colleges typically grant diplomas and certificates rather than degrees, although a small subset of "polytechnic" institutes emerged in the early 2000s that grant baccalaureate degrees with a focus on applied research for industry. A university-college system also exists in the western provinces, which provides four-year undergraduate degree programmes, distinguished from universities mainly by its emphasis on teaching over research. In Canada, many community colleges and polytechnics offer both tertiary-type 5B and non-tertiary post-secondary type 4 programmes, and so international comparisons of tertiary education systems should be viewed with some caution.

Canada has 163 recognised public and private universities and 183 recognised public colleges and institutes, including those granting applied and bachelor's degrees. Private institutions are mainly limited to theological or online universities and career colleges, although a few private non-denominational universities exist in British Columbia and New Brunswick. Publicly funded universities are largely autonomous, set their own admissions standards and degree requirements, and generally manage their financial affairs and programme offerings. Provincial and territorial governments intervene in the areas of funding, fee structures, quality assurance and the introduction of new programmes. In publicly funded colleges, government involvement can extend to admissions policies, programme approval, curricula, institutional planning and working conditions. Vocational education straddles both secondary and tertiary sectors; training may be offered during the last two years of secondary school or in separate specialised schools, or in public and private colleges. Admission requirements for universities and colleges are based largely on secondary school academic performance.

In Canada, education is regulated by the ten provinces and three territories, and there is no national integrated education system. In the 13 jurisdictions, departments or ministries of education oversee the organisation, delivery and assessment of education at all levels. Provincial governments provide on average over $80 \%$ of direct public funding to tertiary education institutions. Although there is no federal department of education, the federal government provides funding for tertiary education in a number of ways, including through transfer payments to provinces and territories (most notably, through the Canada Social Transfer), through direct financial support to colleges and universities (mainly to individual scholars for research), and through direct financial support to students. The federal government also has responsibility for the education of Canada's First Nations population living on reserves. The education policies and the delivery of educational services vary across provinces and territories according to the particular needs and priorities of their respective jurisdiction. Provincial and territorial ministers of education regularly meet and coordinate on initiatives of mutual interest through the Council of Ministers of Education, Canada (CMEC).

\section{Educational attainment}

Educational attainment levels have been rising over time in Canada and across OECD countries. This trend may reflect in part the effects of technological change and globalisation, which have raised demand for highly educated workers and changed the nature of skills needed in the workplace (Riddell, 2001). Canada currently leads the OECD with the highest proportion of adults aged 25-64 that have completed tertiary education at $49 \%$, compared to $30 \%$ for the OECD average (OECD, 2011a). This share rises to $56 \%$ for the cohort of 25-34 year-olds, exceeded only by Korea. However, this ranking reflects a remarkably high community college attainment rate; at 24\%, Canada boasts the highest share of adults with a college (tertiary-type 5B) education, versus the OECD average of $10 \%$ (Figure 2, Panel A). 
Meanwhile, Canada's share of adults with university (tertiary-type 5A) education ranks tenth among OECD countries at $25 \%$ (versus the OECD average of $21 \%$ ), but only fifteenth among adults aged 25-34 (Figure 2, Panel B), portending potential future competitiveness losses.

\section{Figure 2. Population with tertiary education, 2009}

Percentage of the population that has attained tertiary education by age group
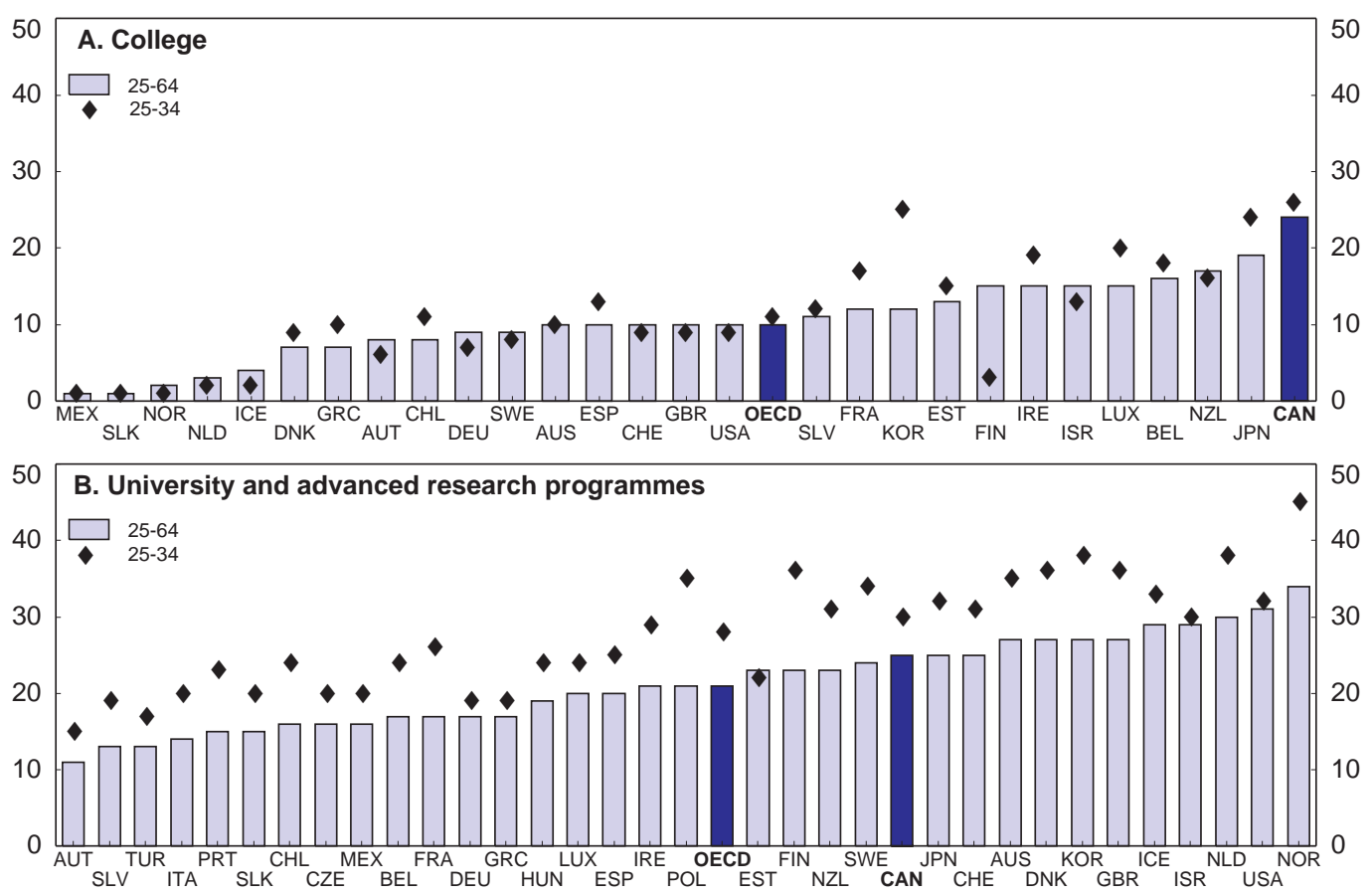

Source: OECD (2011), Education at a Glance 2011.

Tertiary graduation rates depend on various factors, including the degree of access as well as the demand for and returns to higher skills in the labour market (OECD, 2011a). In 2008, Canada's college graduation rate (number of graduates as a share of the graduation-age population cohort) was $28.6 \%$, much higher than the OECD average of $10.4 \%$, whereas its university graduation rate was slightly below the OECD average $(38.6 \%$ ) at $36.6 \%$ (Figure 3$)$. However, university graduation rates have increased substantially from $23 \%$ in 1988 . Furthermore, university graduation rates exceed those of colleges in most provinces across Canada (Figure 3). While Canada's master's and $\mathrm{PhD}$ graduation rates have risen considerably since the early 2000 s, they still ranked in the bottom half of OECD countries as of 2008-09.

Canada's high community college participation rates relative to many other OECD countries likely reflect several factors. One is the structure of education systems in Canada. The systems of public non-degree-granting institutions in Canada were, for the most part, created by provincial and territorial governments in the 1960s to provide labour market preparation programmes as alternatives to the more theoretically oriented programmes of universities. Public universities tend to be concentrated in large urban centres, while colleges in Canada are much more geographically dispersed and are therefore more accessible for Canadians living in rural areas or small towns (note, however, that the percentage of the population that lives within commuting distance of a university varies across provinces and territories). Some degree of measurement discrepancy must also be taken into account when looking at educational attainment: Statistics Canada data on tertiary education attainment includes those with community college diplomas, which does not permit the distinction of some adult education and occupational preparation 
programmes. Because the latter would be classified as non-tertiary post-secondary education for other OECD countries, Canada's community college attainment rates are inflated in cross-country comparisons. A second factor is the unique cégep system in Québec (Box 3). While that system likely explains why Québec's college attainment rates have always exceeded the Canadian average, it is also the case that college graduation rates in almost all provinces and territories are above the OECD average.

Figure 3. Graduation (attainment) rates for college and university programmes ${ }^{1}$

\section{8}
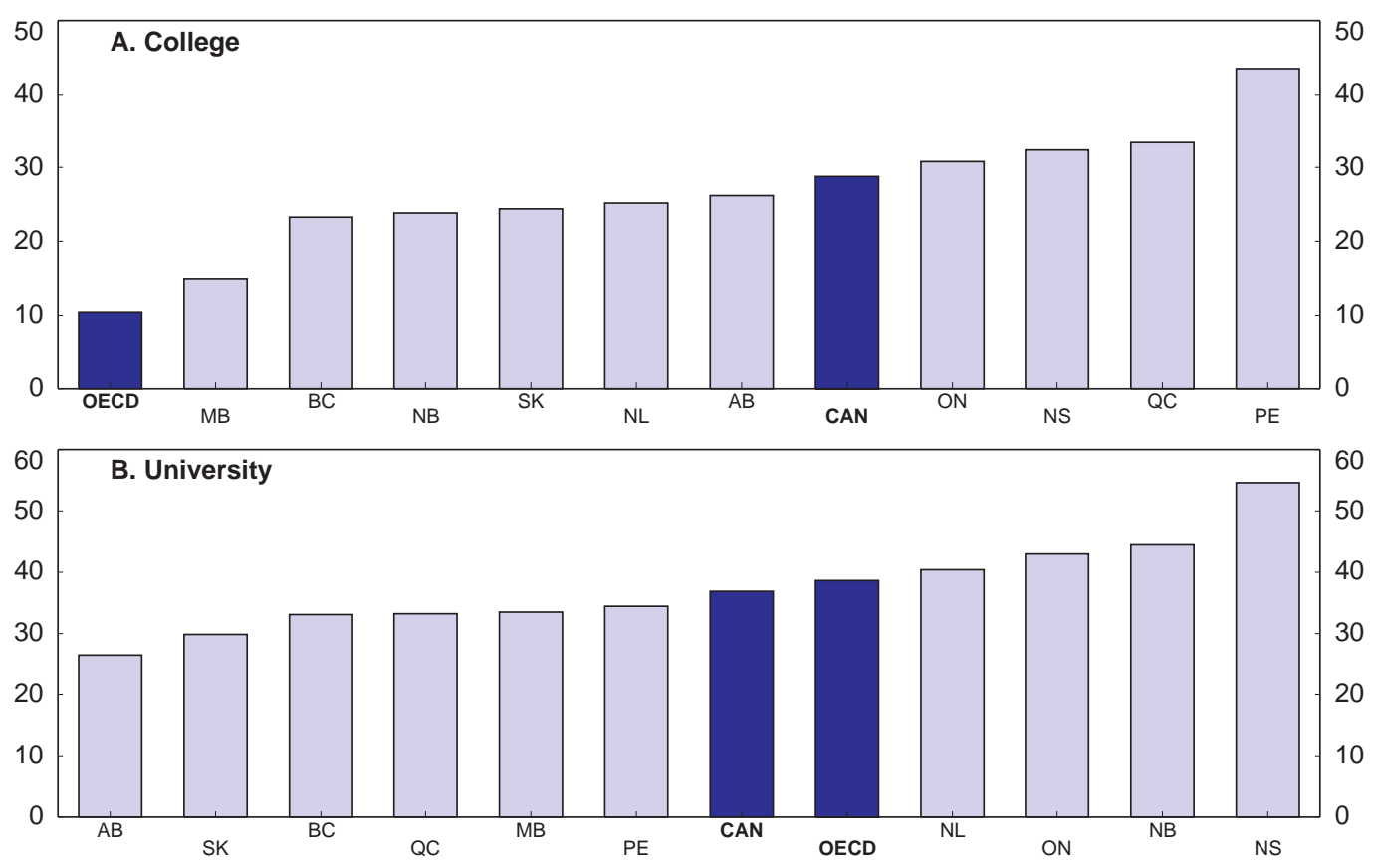

1. The term graduation rate is used in its OECD sense of attainment rate for a specific cohort.

Source: Canadian Education Statistics Council (2011), Education Indicators in Canada: An International Perspective.

\section{Box 3. Québec's education system}

The Québec education system differs from that of other Canadian jurisdictions in that its students finish schooling after 11 years, compared to 12 elsewhere. After completing high school, Québec students can then enter a free public cégep (collège d'enseignement général et professionnel) to pursue either a two-year pre-university stream or a three-year technical training stream. Completion of either stream leads to a College Education Diploma (DEC), which allows admission into a university programme. Both streams contain a general education component, which is equivalent to the twelfth grade of secondary school, while the pre-university stream is equivalent to the first year towards a bachelor's degree. As a result, most Québec university undergraduate programmes last three rather than four years. Since the last year of college technical training is equivalent to the first year of a bachelor's degree programme, various Québec universities have entered into agreements with cégeps to recognise courses from the cégep technical stream for university credit.

Degrees from Québec universities are generally recognised as equivalent to those in other Canadian and foreign universities from the perspective of both the universities themselves and the labour market. When assessing credit transfer eligibilities, universities outside Québec normally recognise credits earned by students who have completed the pre-university cégep stream in the same way as those from other first-year university courses. Students who have completed only one year of a cégep programme may also apply to enter the first year of any four-year undergraduate programme outside Québec. 


\begin{abstract}
Historical and cultural context to education policy in Québec
The cégep and the Université de Québec systems were created in the late 1960s primarily to promote geographical and financial accessibility to post-secondary education at a time when the province was less advanced with respect to the rest of Canada. To fully appreciate the Québec system, it is important to note that Québec defines itself as a society in its own right and not merely as one province among others within the Canadian federation, and therefore made its own educational choices, informed by the most innovative models at the time (Trottier and Bernatchez, 2005).

Québec's higher education policy did and continues to consider accessibility very important, in recognising Article 13 of the 1967 UN International Covenant on Economic, Social and Cultural Rights (of which Canada is a signatory) which states: "Higher education shall be made equally accessible to all, on the basis of capacity, by every appropriate means, and in particular by the progressive introduction of free education". The government has pursued this goal systematically by offering free cégep education and maintaining low university tuition fees. University tuition was frozen from 1972-89, 1990-91 and 1994-2007.

Over time, the Québec government's policy objectives of promoting geographical and financial accessibility have expanded to include quality assurance (Trottier and Bernatchez, 2005). In this context, it decided to maintain free cégep education but to implement minor increases in university tuition of CAD 100 per year from 2007-08 to 2011-12, along with further increases of CAD 325 per year from 2012-13 to 2016-17. These increases are complemented by an expansion of student financial aid. These tuition increases will result in a return to 1968 tuition levels in real terms and are intended to increase the student contribution to university financing with a view to a more "equitable" distribution of costs, without worsening the province's standing relative to where it was when the UN pact was signed (Comité consultatif sur l'accessibilité financière aux études, 2011). Nonetheless, they have met with resistance from the student population.
\end{abstract}

Canada has a large community college sector, accounting for over half of Canada's TEIs, as compared to about $40 \%$ in the United States (Skolnik, 2004). The sector was developed in the 1960s to provide cost-effective access to tertiary education for the baby-boom generation. Over time the college sector has continued to expand and broaden its mandate by diversifying its student base and educational offerings. Some colleges have now become recipients of certain federal research grants, traditionally the realm of universities. Such developments mirror the growth of non-university sectors in other OECD countries in order to meet the increasingly diverse needs of the labour market, given profound structural changes, while allowing governments to limit the cost of providing tertiary education to a growing student body through shorter programmes (Santiago et al., 2008).

Over time there has also been an increasing flow of student transfers between the university and college sectors. The community college systems in British Columbia and Alberta allow students to complete either a diploma programme or two years of academic course work towards a bachelor's degree. Those who choose the latter stream may then complete the third and fourth years at a university to earn the degree. The colleges in these provinces thus operate as hybrid institutions, providing not only technical education but also general academic education that can be applied towards a university degree. This system grew out of perceived changes in the skill mix demanded by the labour market, as well as governments' approach to expanding access to university at a lower cost. In other provinces, college courses must be evaluated for credit equivalency during the university admissions process. In Ontario, colleges have traditionally been permitted to operate only in areas not covered by university programmes, although individual partnerships have been formed between universities and community colleges.

University graduates are also complementing their degrees with college diplomas to improve their employability. These so-called "reverse transfers" began in the early 1990s as the economy's changing occupational structure and skill requirements drove up labour-market demands for individuals possessing a combination of technical/vocational and traditional analytical skill sets (Crocker and Usher, 2006). In general across OECD countries, workers are increasingly seeking to update their skills, and many choose to select a variety of courses from the most suitable providers, rather than committing to a fixed curriculum at any one institution (Santiago et al., 2008). 
The rapidly changing needs of the knowledge economy make it increasingly important to have a flexible tertiary education system that can provide continuous learning opportunities to students with a diverse range of backgrounds throughout their entire career. This system should allow for various entry and re-entry pathways for adult learners seeking to upgrade their skills. Longitudinal data from the Youth in Transition survey reveals that roughly $20 \%$ of college and university students in Canada leave their studies by the fourth year of their programme, but about half to two-thirds of these individuals return within four years of leaving (Finnie et al., 2012). Of those that return, 30-50\% switch to a different institution. These findings suggest that Canada's tertiary education system appears to already accommodate a variety of student trajectories, but flexibility could be improved further.

Flexibility could be enhanced by improving the "articulation" between and among colleges and universities to facilitate credit transfer where complementarities exist. First- and second-year university credits are transferable among nearly all Canadian universities in keeping with CMEC's Pan-Canadian Protocol on Credit Transfer (1995). However, the ease with which credits can be transferred between colleges and universities, and between provinces varies across regions. Certain provinces such as British Columbia and Alberta have taken positive steps in this direction. For example, Alberta has developed the Campus Alberta model to recognise the particular needs of its learners, who tend to be older due to attractive employment opportunities in the resource-based economy. ${ }^{2}$ The model allows credit transfers across institutions, including recognition of trades training and online learning, so students can design their own programmes from the different institutional offerings available in the province. Inter-provincial transfer agreements have also been established among western and among Atlantic provinces. These developments should serve as a model for other provinces to strengthen transfer arrangements both within and across jurisdictions.

In recognition of this need, a CMEC Working Group on Credit Transfer was established in 2002 to move towards a Pan-Canadian system over time, with a current focus on improving coordination within individual provinces and territories. Cross-country consultations have been carried out through the Pan-Canadian Consortium on Admission and Transfer, facilitating a multitude of reciprocal arrangements for credit transfer between TEIs. As proposed by Skolnik (2004), transfers could also be greatly facilitated if colleges and universities employed a common course numbering system, as exists in several US states.

The imminent retirement of baby boomers implies that tertiary participation rates will need to rise in order to maintain the supply of skilled workers, as discussed later. Statistics Canada projections indicate that the population of 15-19 year-olds reached a peak in 2009 and is set to decline steadily until almost 2020 , suggesting the supply of new tertiary graduates will decline at constant participation rates. ${ }^{3}$ Many provinces have recognised this challenge and set explicit objectives to increase post-secondary education (PSE) attainment rates. For example, the 2010 Ontario budget sought to raise the attainment rate from $62 \%$ to $70 \%$ by 2020 . Given that overall participation rates are already quite high, there is a growing consensus that achieving such growth will need to come from greater inclusion of currently under-represented groups, such as students from families with low incomes and/or no history of PSE, Aboriginal students, students with disabilities and mature students.

\section{Access to higher education}

The decision to pursue tertiary education depends on several factors, including labour-market conditions, parental attitudes towards higher education, academic performance and literacy skills, the presence of motivational teachers in schools, the geographic location of TEIs and financial barriers.

2. Emery et al. (2011) find evidence that resource booms tend to lower PSE enrolment in Alberta in the short term but only change the timing of schooling, with no long-lasting negative effects on attainment.

Statistics Canada Medium Growth Scenario, CANSIM Table 052-0005. 
Results from Statistics Canada's 1999 Youth in Transition Survey found that 18-20 year-olds perceived financial barriers as the most important factor affecting their decision to pursue tertiary education (CCL, 2009). Indeed, wealthier Canadians are nearly twice as likely to go to university as poorer ones: while $46 \%$ of 19 year-olds from high-income families enrol in university, only $25 \%$ from low-income backgrounds do so, a gap that has been largely unchanged over the past 15 years (Berger et al., 2009). However, as research on access to tertiary education progressed, it became more evident that barriers such as family background (particularly parental educational attainment) and high-school performance were among the strongest predictors of tertiary education participation in Canada.

Community college participation is more evenly distributed across socio-economic groups and less linked to family income (Figure 4). This outcome may reflect the greater geographic dispersion of colleges compared to universities (although, in some provinces, a large majority of the population lives within commuting distance of a university). For rural and low-income students, the costs of higher education can depend to a large extent on their proximity to a TEI. Students located beyond commuting distance would necessarily face greater financial obligations in the form of accommodation costs. Indeed, students from rural and urban areas are equally likely to attend college, but urban students are significantly more likely to attend university (OECD, 2010a). Furthermore, most inhabitants of northern regions do not have TEIs within commuting distance (CCL, 2009), which may explain why Canada offers a relatively high proportion of tertiary education courses conducted online (OECD, 2005). The data also indicate that college participation rates for young adults trended down from the late 1990s to 2008 for all family income groups (Figure 4, Panel B), although overall college enrolments increased slightly. This may reflect strong

Figure 4. Participation rates in university and college

By family income among 18 to 24 year-olds, per cent
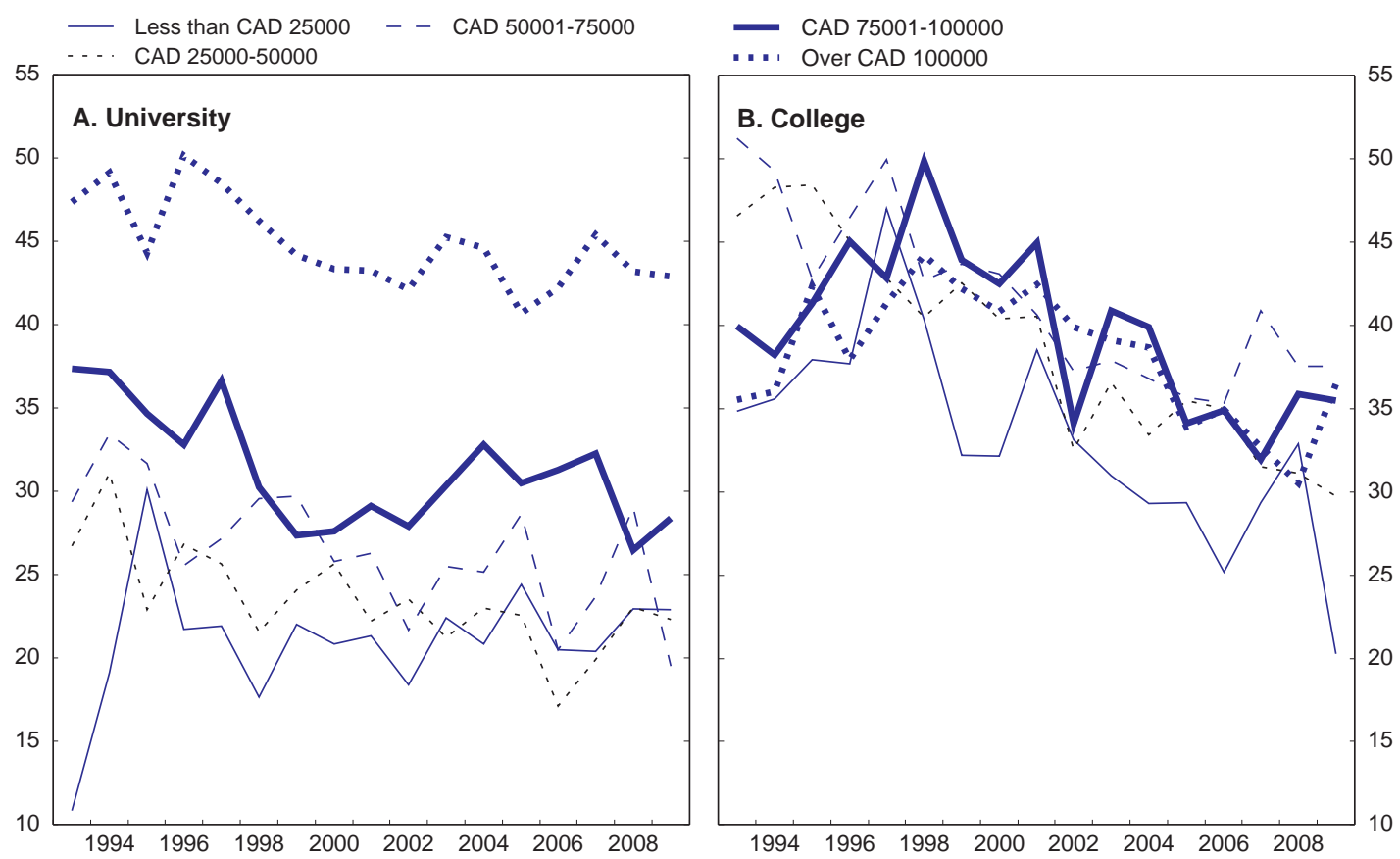

Source: Statistics Canada, from Survey of Labour and Income Dynamics. 
labour-market conditions over this period: the unemployment rate for secondary school graduates dropped from $9.8 \%$ to $6.4 \%$ (although it has since moved back up to $7.9 \%$ in 2011 ), with a similar sized improvement for those with less than high school credentials. Cyclical fluctuations in the economy may have a larger impact on enrolment in college than in university, given the sector's greater focus on applied training for the labour market.

More equal participation in college education across socio-economic groups may also reflect a greater responsiveness of college programmes to the needs of students from rural, low-income and Aboriginal backgrounds. Given their greater presence in rural areas, community colleges can more easily cater to the training needs of local communities. Compared to universities, colleges' shorter-term focus on developing skills for current industry and labour-market demands may also provide a greater appeal to students from financially disadvantaged families.

More recent research suggests that it is non-financial factors such as family background and high school performance that have the greatest influence on tertiary participation in Canada (Finnie and Mueller, 2008; Johnson, 2008). While family income plays a significant role in determining tertiary participation, its effect appears to be dominated by parental education levels, which is in turn highly correlated with students' academic performance in high school (Finnie and Mueller, 2008). Results from an OECD (2010a) study indicate that among Canadian students from the 2000 PISA cohort, those with university-educated parents were 4.6 times more likely to enter university after accounting for other factors, whereas the effects of parental income and occupation were small. Among 18-24 year-olds whose parents completed a university degree, about $80 \%$ consistently enrol in tertiary studies (Figure 5 ). These findings could reflect the possibility that highly educated parents expect more of their children, provide a more intellectually engaging environment for them and teach them better work habits.

Figure 5. Post-secondary participation rates by parental education

Among 18 to 24 year-olds, per cent

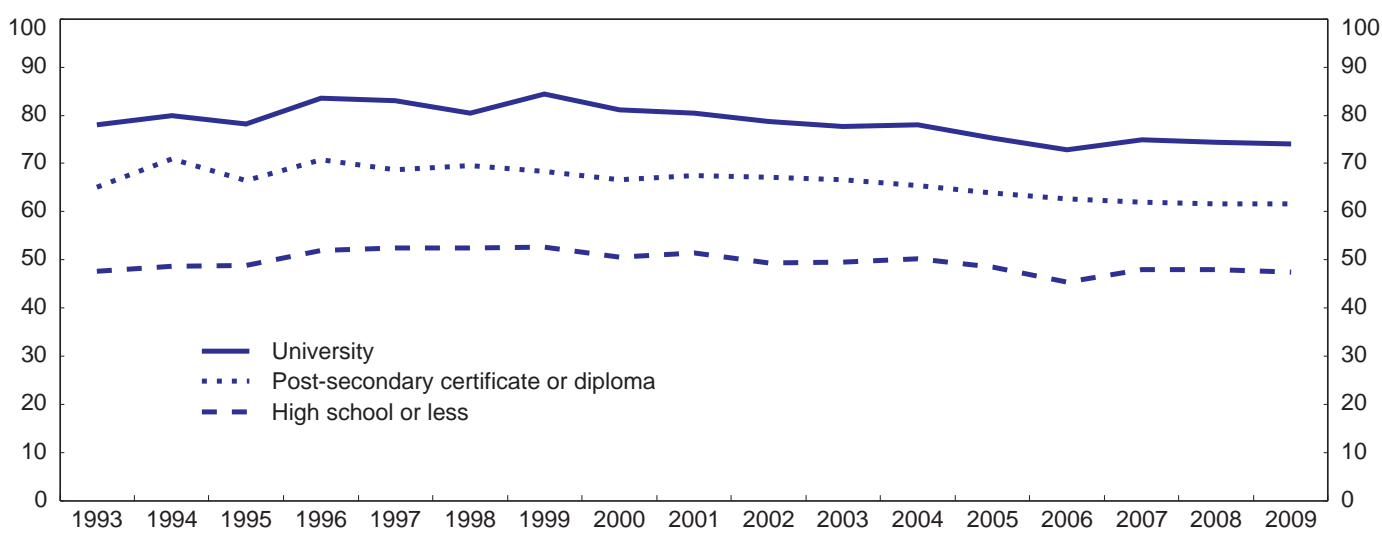

Source: Statistics Canada, from Survey of Labour and Income Dynamics.

The importance of family income in determining tertiary participation reflects in part the greater liquidity constraints facing lower-income households, which can largely be addressed by an effective student-loan system. The finding that family income is only weakly associated with tertiary education attendance suggests that Canada's financial-aid system is generally successful at providing funds to qualified students who are otherwise unable to pay, and/or that tuition levels are at a level that do not constitute an effective barrier to studying. However, a number of studies find support for the proposition that disadvantaged students face a different demand curve for higher education and require a higher financial rate of return to enrol than those from wealthier backgrounds (Carmichael and Finnie, 2008; 
Palameta and Voyer, 2010). These students may also undervalue education due to a lack of information on its benefits and costs. This difference in "willingness to pay" makes students from poorer families more sensitive to changes in the cost of education and potentially more averse to taking on debt, neither of which can be addressed by even an ideal student-loan system. ${ }^{4}$ These findings imply that achieving equal access may additionally require the provision of grants to students from disadvantaged backgrounds.

\section{Overcoming barriers to equitable access}

According to the 2003-04 Canadian Post-Secondary Student Financial Survey, tuition accounts for the largest share of student expenses at 34\%, followed by accommodation and food at $30 \%$, with other costs such as books, computers and transportation forming the remainder. In general, tuition fees at TEIs are regulated provincially, with significant differences in the level and variation over time across the country (Figure 6). Between 1997-98 and 2010-11, but especially in the early years of that period, university tuition fees increased in real terms in most provinces, by an average of about $40 \%$, although declines took place in Newfoundland and Labrador, and Manitoba where tuition freezes were in effect. By 2008-09, average university tuition fees in Canada were roughly in the middle of the range for OECD countries reporting on this measure (Figure 7).

One way of addressing the issue of the impact of rising costs on access to tertiary education would be to move to an income-contingent loan repayment system, as in Australia and the United Kingdom. Under this system in its pure form, students do not face any upfront tuition costs; the fees are covered by the government through a loan that is paid back after graduation. Because loan repayments are dependent on income levels, the amount of subsidy increases for those with lower lifetime earnings, as long as unpaid loan balances are discharged after a given amount of time. Evaluations of Australia's loan system a decade after its introduction found that socio-economic background had become less important in determining tertiary education participation (Santiago et al., 2008). However, moving to such a system involves very high initial costs to cover student tuition fees until repayments begin to take effect, which may create challenges for provinces that presently face high public debt levels.

Figure 6. Average tuition fees by province

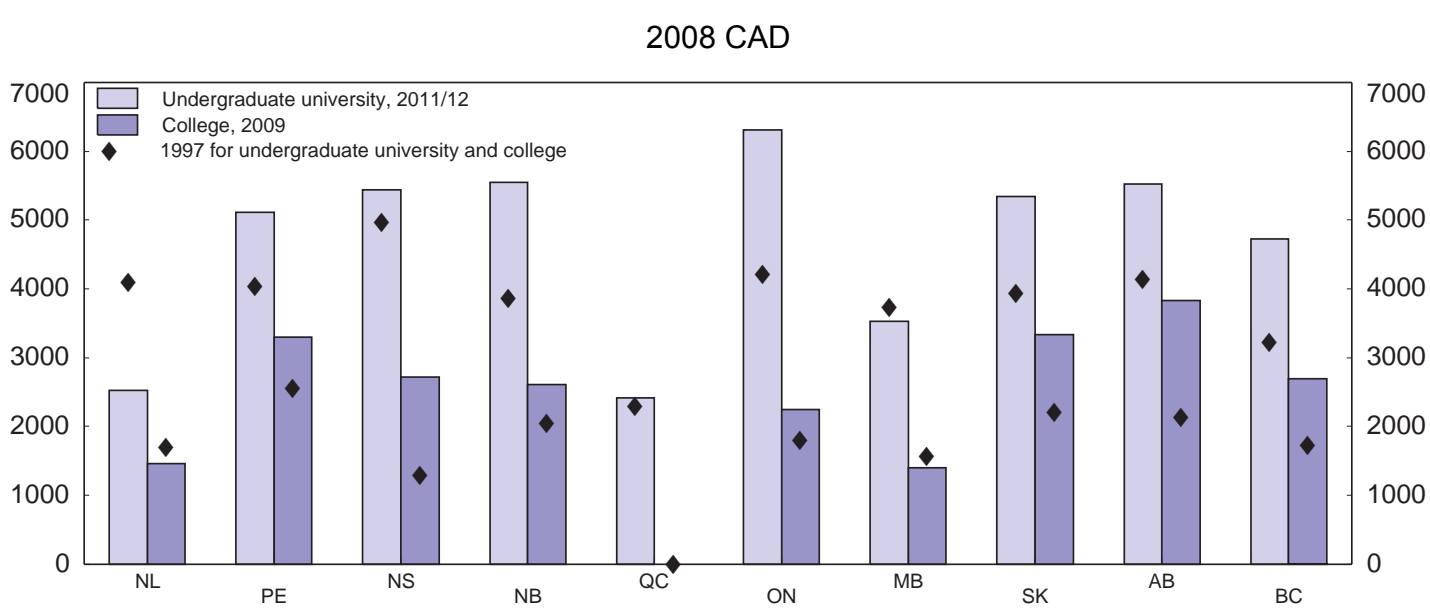

Source: Canada Millennium Scholarship Foundation (2009), The Price of Knowledge; Manitoba Council on Post-Secondary Education (2011), Statistical Compendium; and Statistics Canada.

4. Palameta and Voyer (2010) find that while disadvantaged groups may be more prone to loan aversion, that may be linked to lower numeracy skills, a tendency to discount future benefits excessively and doubt about the returns to university education. 
Figure 7. Average annual university tuition fees for full-time students

2008/09, in equivalent USD converted using PPPs

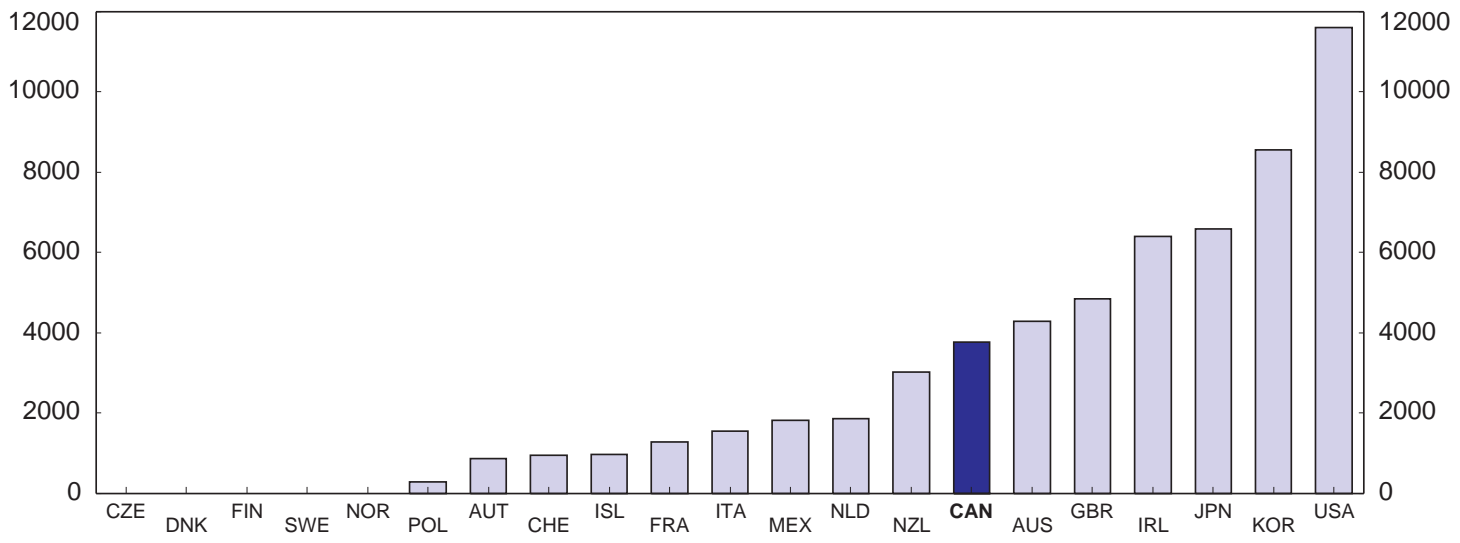

Source: OECD (2011), Education at a Glance 2011, table B5.1.

High or rising tuition fees on their own may not pose a significant barrier to low- or modest-income students if they are adequately matched by financial assistance to support them. In general, tuition differentials across Canadian provinces do not appear to drive variations in tertiary education participation (Johnson, 2008), again suggesting that the student financial-aid system is effective and/or that tuition levels are not high enough to pose a financial barrier. Nonetheless, despite evidence indicating that tertiary participation in Canada is price inelastic after accounting for other socio-economic factors, several studies suggest that increases in the cost of education may have a larger impact on students either from low-income families or whose parents have no higher education (Junor and Usher, 2004; Corak et al., 2003; Coelli, 2005; Johnson, 2008). Reducing the price of tertiary education could therefore boost demand among these groups. Rather than blanket tuition cuts, this would be achieved most efficiently by increasing the provision of non-repayable grants directly to socio-economically disadvantaged students, once again given their greater debt aversion. Since university attendance increases with family income levels, the alternative of lowering or freezing tuition fees would act regressively to provide greater benefits to the affluent.

A large fraction of student financial assistance in Canada is provided in the form of subsidised loans and universal tax credits (Box 4) (OECD, 2011a). Student loans account for the largest share of aid provided, although it is worth noting that since the majority ends up getting repaid, the net cost of outstanding loans is substantially lower than their value. The actual cost of a student loan, which includes the interest subsidy (see Box 4) and cost associated with default, is estimated to be $30-40 \%$ of the loan value (Berger et al., 2009). ${ }^{5}$ According to Berger et al. (2009), government spending on educational tax credits represents roughly one-third of all student support and has grown faster than any other form of public financial assistance since the 1990s.

5. Student-loan default rates have declined substantially to $14.7 \%$ in $2008-09$, from $38 \%$ in $2001-02$. Students in private career colleges have the highest default rates at $29 \%$, followed by those from community college at $17 \%$ and university graduates at $9.5 \%$. 


\section{Box 4. Financial support for students in Canada} education:

Federal, provincial and territorial governments provide financial aid in various forms for students to pursue tertiary

- Loans: With the exception of Québec, the Northwest Territories and Nunavut which operate their own programmes, students submit a single application to be considered for both federal and provincial/territorial financial assistance to the programme in their province or territory of residence and eligibility is determined based on an assessment of their level of need (i.e. educational costs incurred less financial resources). While provinces/territories (with the exception of those noted above) follow the same basic approach to assessing need, differences exist in the types of student expenses and resources that are recognised, as well as in the cost of living across the country and hence, in the amount of assistance awarded. The amounts provided through these programmes are shared between governments, with $60 \%$ of the aid provided by the federal government and $40 \%$ by the provincial government. Students are not charged interest on loans while studying and are required to begin repaying their debt six months after leaving school. Interest begins to accumulate on federal and provincial loans from the month after the completion of studies, at either a fixed rate (prime $+5 \%$ ) or a floating rate (prime $+2.5 \%$ ) for federal student loans (interest rates vary for provincial student loans).

- Grants and loan remissions: Applicants for student loans are automatically assessed for eligibility to receive various federal and provincial non-repayable grants and provincial loan remissions. Eligibility conditions vary according to the province or territory of residence. Up-front grants are available for low- and middle-income students from the Canada Student Grants Program (CSGP) and several provincial programmes. Loan remissions, which are offered at the end of a year of study or following the successful completion of a programme, and which reduce the amount owing on a student loan, also comprise a significant portion of the available aid. Several other kinds of grants are available for under-represented students such as, for example, those with disabilities and dependents, those from rural areas, Aboriginal students and adult learners.

- $\quad$ Repayment Assistance Plan (RAP): This was introduced in August 2009 to offer relief on student debt repayments during periods of low income due to unemployment or under-employment. Borrowers under financial distress must opt into the RAP, and eligibility is determined by income and family size. The programme determines the repayment amounts on a sliding scale; they must not exceed $20 \%$ of the borrower's income. Persistent eligibility for the RAP for 15 years can also lead to complete forgiveness of the debt.

- $\quad$ Merit scholarships: The federal government, and all provinces and territories offer merit based scholarships based on various academic and other criteria.

The following federal programmes and grants are eligible to all students (unless otherwise noted) for full- or part-time studies in a university, college, and in some cases, a trade or apprenticeship programme:

- $\quad$ Registered Education Savings Plan (RESP): Introduced in the early 1970s, this measure allows individuals to make after-tax contributions to a savings account, which can be used to fund a child's tertiary education. Investment income earned within the RESP is taxed in the hands of the student at the time of withdrawal (note that some provinces now also provide a grant to match a portion of RESP contributions).

- Canada Education Savings Grant (CESG): Implemented in 1998, applicants to the CESG can have up to CAD 7200 directly deposited by the federal government into an RESP. There are two types of CESG: Basic and Additional. Through the Basic CESG, the federal government makes payments of $20 \%$ on RESP contributions made in respect of an eligible beneficiary until the end of the year in which the beneficiary turns 17 . The Additional CESG is a payment (over and above the Basic CESG amount) of either $10 \%$ or $20 \%$ on the first CAD 500 or less of annual RESP contributions up until the end of the year in which the beneficiary turns 17.

- Apprenticeship Grants: Created in 2007, the Apprenticeship Incentive Grant is a taxable grant of CAD 1000 per year for registered apprentices who have successfully completed their first and/or second year of an apprenticeship programme in a designated Red Seal trade, up to a maximum of CAD 2000 per apprentice. The Apprenticeship Completion Grant is a CAD 2000 taxable grant available to registered apprentices who successfully complete their training and obtain a journeyperson certification in a designated Red Seal trade.

- $\quad$ Canada Learning Bond (CLB): This was introduced in 2005 and grants low-income families up to CAD 2000 in the form of RESP contributions that can be used to finance a child's tertiary education.

- Tax credits: Tax credits are available to tertiary students in recognition of the costs associated with tertiary study, including tuition fees, months of full- or part-time study and textbooks. Additionally, tax credits that refund a portion of tuition fees paid are available following completion of studies for students who choose to stay or relocate to other provinces. Unused tuition, education and textbook tax credits of up to CAD 5000 annually may be transferred to a parent, grand-parent or spouse, and any excess amount may be carried forward indefinitely. 
In principle, these tax credits offset some of the disincentive to personal skills acquisition that is created by a progressive tax system, since the earnings premium that normally results from higher education credentials is taxed at a higher rate. The withdrawal of in-work tax credits when full-time studies are pursued may additionally raise marginal effective tax rates, creating an overall under-investment in skills. However, because tax credits can be claimed only upon filing an income tax return and are non-refundable, students do not benefit from them until after the academic year is over; many students may not begin to claim taxable income until well after graduation. As a result, tax credits do not provide financial support to many students at the time of their greatest need. Based on analysis by Usher and Duncan (2008), about $45 \%$ of all tax credits are used by the student in the year they are earned, whereas $35 \%$ are transferred to other family members and $20 \%$ are carried forward to future years. Like all universal support for students, tax credits are used disproportionately more by high-income families because their children are more likely to pursue tertiary studies. Furthermore, because the size of the tax credit varies with the level of tuition fees, students in higher-cost programmes are able to claim a larger benefit.

The federal government offers various savings incentives as well (Box 4), which also disproportionately benefit high-income families, given that others are less likely to have the means to save. In 2008, about 230000 individuals benefited from RESP withdrawals to fund their studies, representing $11 \%$ of eligible students. Some provinces have followed suit in recent years by offering their own top-ups to the RESP savings of families. While the Canada Learning Bond (CLB) targets low-income families, the take-up rate remains low (at $21.8 \%$ of eligible beneficiaries in 2010, compared to $42.8 \%$ for the Canada Education Savings Grant), although it has increased steadily since the programme's inception.

In recognition of the fact that individuals' ability to service their student debt following the completion of their studies is contingent upon their labour-market outcomes, the federal government introduced the Repayment Assistance Plan (RAP) (Box 4) in 2009 (most provinces now offer RAP as well). The RAP is an opt-in programme, and eligible candidates are subject to a more affordable monthly payment based on their family income and family size. Governments in Canada also provide funding to non-government organisations, such as Pathways to Education Canada, which work to provide targeted support to individuals facing non-financial and financial barriers. The federal government funds as well a variety of groups through the Education Savings Community Outreach Program.

\section{Increase the targeting of financial aid to those in need}

The value of need-based aid provided has risen since 2001-02, after falling in the late 1990s. Between 2004 and 2008, the amount of non-repayable need-based aid climbed substantially, reflecting the introduction of new government grant programmes designed to improve support for under-represented groups. Limits on the amount of aid that can be provided per student are not indexed to inflation but are re-adjusted periodically. In 2007-08, federal and provincial governments provided a total of CAD 4.4 billion in need-based aid, an average of CAD 10500 per recipient, of which two-thirds represented net loans, $22 \%$ grants and $12 \%$ loan remissions.

In general, a student's assessed need is covered through loans and grants. For the federal portion of assistance, grants are awarded first to those who are eligible, and any outstanding need is met with loans up to a maximum loan limit. Where loans are awarded first, in some cases provincial grants reduce the amount of the loan to a predetermined maximum. Canada provides a relatively low share of total direct subsidies (i.e. excluding tax credits) in the form of grants: $3.1 \%$, compared to the OECD average of $11.4 \%$ (Figure 8 , Panel A). Meanwhile, the share distributed in the form of loans is somewhat above average, at $11.6 \%$ (Figure 8, Panel B). These calculations underestimate the share of non-repayable assistance provided, however, since they do not incorporate loan remissions, which become a form of grant. 
Figure 8. Public subsidies for education to private entities for tertiary education 2008, percentage of total public expenditure on tertiary education
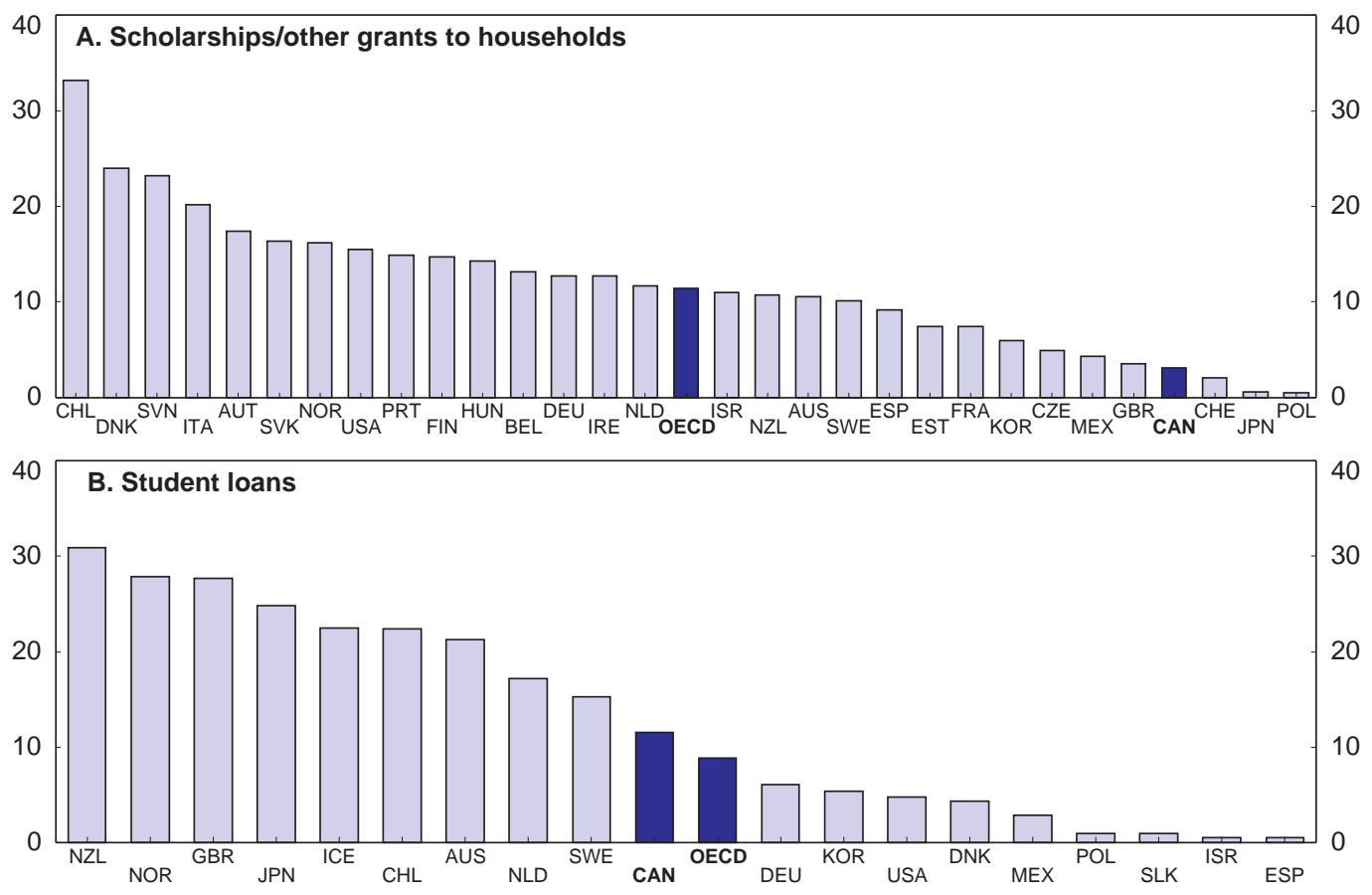

Source: OECD (2011), Education at a Glance 2011, table B5.3.

The current aid system views financing for tertiary education as a shared responsibility, and so students are expected to make personal or family contributions towards the cost of their studies. Only about one third of college and university undergraduate students receive a government loan or grant in any given year of their studies, and no more than half of all students from families earning less than CAD 50000 per year receive financial aid (Berger et al., 2009). While government financial assistance does not always fully fund the cost of studies, since 2005 student-aid limits have been increased, expected parental contributions reduced, and additional assistance provided in the form of grants to improve the coverage of need, reducing the proportion of student aid recipients receiving the maximum amount of the federal student loan from over $50 \%$ to less than $30 \%$. Single parents accounted for the largest share of students with unmet needs, who more generally tended to be older and female. Unmet needs can lead students to take on private debt or increase hours worked at part-time jobs, while adversely affecting persistence and completion (McElroy, 2004). These findings indicate that, while the proportion of those at assistance limits is lower than in previous years, student assistance policies should be re-evaluated periodically to ensure that aid limits realistically address the costs faced by students, in particular those with dependents.

Improving equality of access to tertiary education depends on the ability to deliver information to low-income families to help them plan and understand the costs and benefits of higher education, and to do so at an early enough stage to influence their aspirations and preparations. As proposed by Berger et al. (2009), one way to do this is through the Canada Child Tax Benefit (CCTB) and National Child Benefit Supplement (NCBS) programmes. These measures automatically provide monthly financial support to families earning below a certain income threshold (provided that they file income tax returns) who have children under the age of 18. Even though eligibility for the Canada Student Grants Program is not based on precisely the same income thresholds as the CCTB and NCBS programmes, they could be used to identify potential aid recipients early on. These families could then be delivered information about 
tertiary education and financial-assistance options well in advance of the application point. They could furthermore be automatically enrolled in the Canada Learning Bond (Box 4), which is currently an opt-in programme.

Changing the aid application process to separate loans from grants could also help lower financial barriers. Currently, tertiary students are required to apply for a student loan and a government grant in one application. Given evidence that low-income students are more likely to be debt-averse, they may rely more heavily on non-repayable student grants to finance their studies. Under the current system in which grants can be accessed only via a loan application, many who would benefit from a grant may not even apply due to a lack of awareness or willingness to take on debt. While current needs assessments for student assistance take into account parental income, parental education levels should also be considered, with greater targeting of so-called "first-generation" students. For example, Ontario offers a first-generation grant for students demonstrating financial need whose parents have no history of PSE.

\section{Outcomes of the education system}

\section{Skills to meet labour-force needs}

The rise over time in educational attainment in Canada corresponds broadly to demands from the labour market. The shift from a manufacturing-based to a knowledge-based economy over the past few decades has significantly affected the way businesses operate and the skills that they seek in their employees. It is now widely believed that tertiary graduates require both generic and specialised technical skills to remain competitive and adapt to changing job requirements (Axelrod, 2002). A government report (HRSDC, 2008) found that between 1987 and 2007 the employment share of occupations usually requiring university education rose from $13.1 \%$ to $17.8 \%$. Although occupations normally requiring only college or apprenticeship training account for almost twice as many jobs in the economy, their share in total employment declined slightly from $35.8 \%$ to $33.6 \%$.

In Canada, as elsewhere, individuals' labour-market outcomes generally improve with higher educational attainment. The average earnings advantage for employees with college education was only $11 \%$ relative to those with upper-secondary or non-tertiary post-secondary education in 2008, ranking Canada 21 st out of 26 OECD countries for which data for this indicator were available (Figure 9). The below-average premium may again reflect Canadian colleges' inclusion of programmes that would be defined as "non-tertiary post-secondary" by international convention. It may also reflect comparatively high earnings possibilities for those with no post-secondary credentials, particularly in the resource sectors. Indeed, in 2008 college graduates in Alberta and Saskatchewan had negative or near-zero earnings advantages over those with only high-school education. Another factor that may explain the relatively low premium for college graduates is the large number available in the labour market. Canada is somewhat unique in having such a large portion of its tertiary graduates with college level credentials. Meanwhile, the $70 \%$ premium earned by university graduates in Canada is slightly higher than the OECD average of $63 \%$ (Figure 9). After taking into account the costs of training (including the opportunity cost of foregone earnings), the annual private returns to tertiary education are calculated to be $11.9 \%$ for men and $11.1 \%$ for women, slightly below the OECD averages of $12.4 \%$ and $11.5 \%$, respectively (OECD, 2011a). These estimates may again reflect the lower earnings of a relatively large share of community college graduates in Canada, combined with a low share of university graduates compared to other countries.

The evolution of relative earnings and employment rates over time can signal any imbalances in the demand and supply of different skill levels in the labour market. When the entire population with tertiary credentials is considered, the earnings premium of those with college and university education relative to high-school graduates appear to have remained fairly stable since the late 1990s, with a slight uptick observed in the advantage of university graduates in 2009 (Figure 10, Panel A). While at first glance these 
patterns suggest that the supply of different skill levels has generally kept pace with demand over this period, they mask diverging trends at the disaggregated level. For example, Bonikowska et al. (2011) find that the earnings premiums of Canadian-born university graduates have increased significantly since 1991, whereas those for university-educated immigrants have declined over the same period.

Figure 9. Relative earnings of 25-64 year-olds with tertiary education, 2009

Upper secondary and post-secondary non-tertiary education $=100$
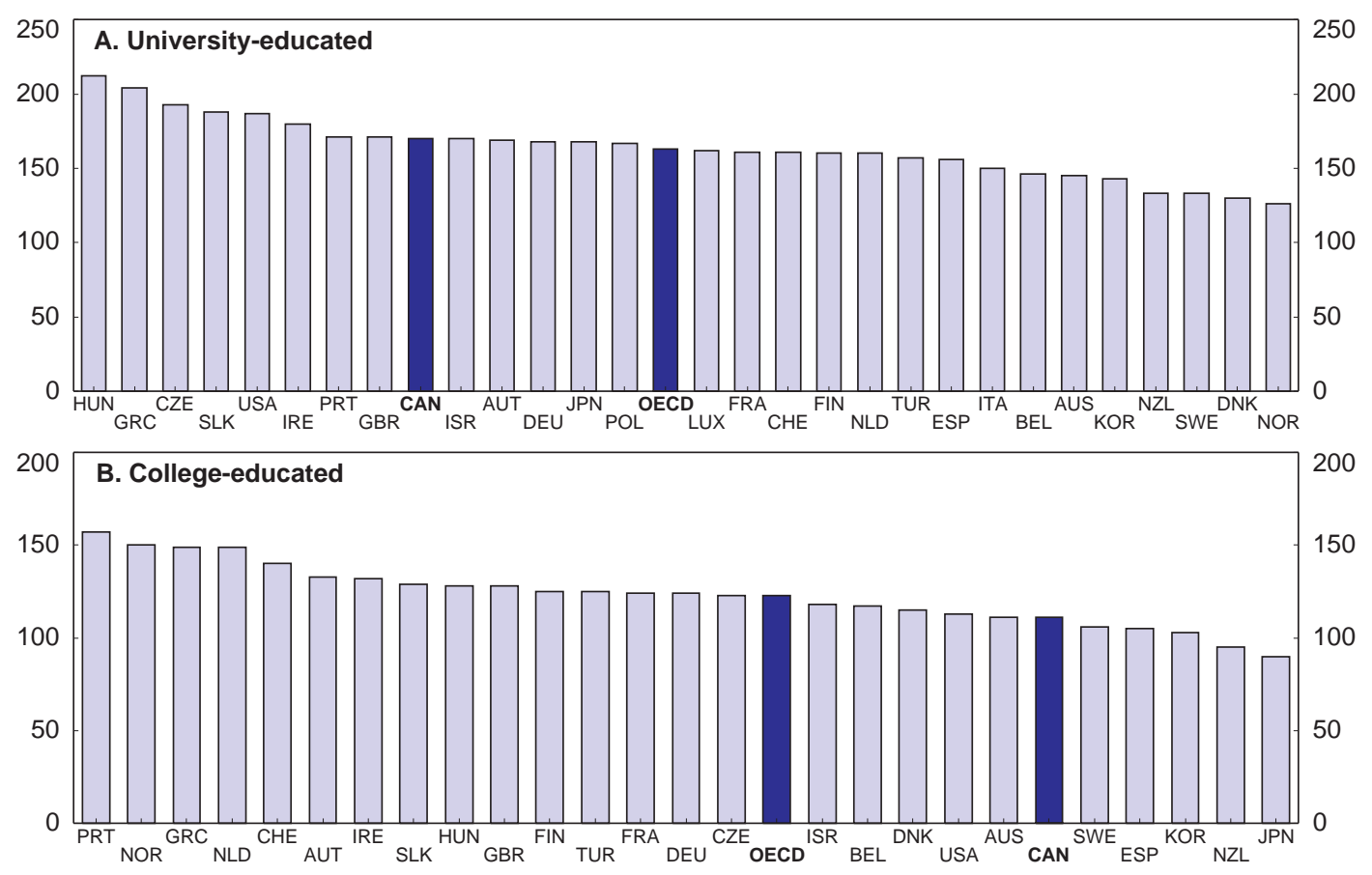

Source: OECD (2011a), Education at a Glance 2011, table A8.1.

Figure 10. Earnings premium and employment rate relative to high school graduates

Per cent

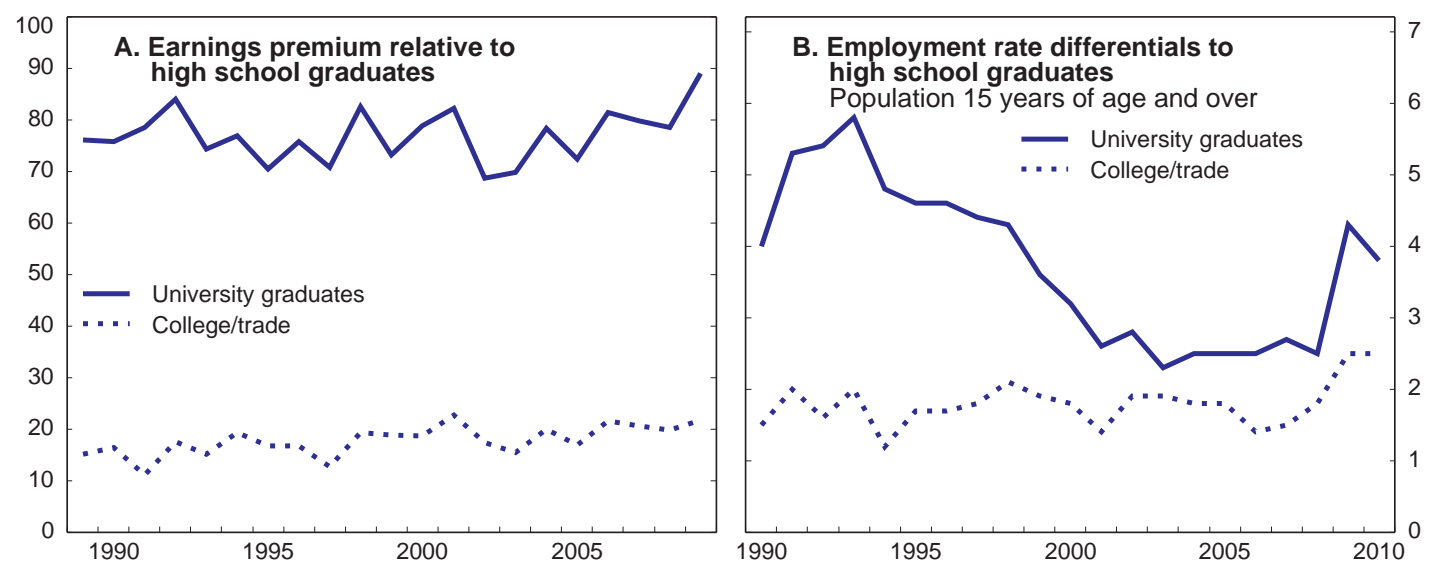

Source: Statistics Canada, Cansim database, tables 202-0106 and 282-0003; and Education Indicators in Canada: Report of the Pan-Canadian Education Indicators Program, April 2011. 
Whereas comparatively high and rising earnings premiums of university graduates suggest there could be net private benefits to boosting rates of participation at this level relative to colleges, a number of other indicators paint a less clear picture. First, while university graduates enjoy higher employment rates relative to those with either high school, college or vocational education, this margin declined substantially from 1993 to 2003 (Figure 10, Panel B). This pattern reflects sharper improvements in the employment rates of those with secondary school and college or trades education over this time period than those with university degrees. Although the reasons for this are uncertain, it may reflect strong growth in the manufacturing sector, where workers have predominantly high school, college or trades qualifications. This sector accounted for almost one quarter of all jobs created over this period of exchange-rate depreciation. As the currency began to appreciate in the early 2000s, relative employment rates of university graduates steadied and have improved considerably since the global financial crisis in 2008 .

Also, the proportion of university-educated workers in lower skilled jobs increased from $35 \%$ in 1997 to $39 \%$ in 2007 (Table 1), although this share also rose for college-educated workers (34\% to 37\%). These developments may signal an over-supply of both university and college graduates, at least in certain fields, relative to employer needs, in other words some mismatch. The findings may alternatively be explained by: temporary transitions after graduation; high levels of immigration; job loss; skills deficiencies among some graduates; or certain graduates choosing fields of study for which there is limited demand (Leuven and Oosterbeek, 2011; Quintini, 2011). These outcomes may also reflect better wage prospects in sectors requiring lower skill levels, such as oil sands development (HRSDC, 2008). Nonetheless, even in lower skilled occupations, university graduates tend to earn higher wages than those with less education, presumably reflecting higher productivity (HRSDC, 2008). Compared to the OECD average, Canada has a below average rate of over-qualification and a considerably above average rate of under-qualification (Quintini, 2011).

Table 1. Employment of tertiary graduates by skill level

\begin{tabular}{lrr}
\hline University graduates & $\mathbf{1 9 9 7}$ & $\mathbf{2 0 0 7}$ \\
\hline Management or occupations usually requiring university & $65.0 \%$ & $60.8 \%$ \\
Occupations usually requiring college or apprenticeship training & $19.2 \%$ & $20.2 \%$ \\
Occupations usually requiring high school & $13.1 \%$ & $15.4 \%$ \\
Occupations usually requiring on-the-job training & $2.8 \%$ & $3.6 \%$ \\
\hline College graduates & & $20.2 \%$ \\
\hline Management or occupations usually requiring university & $22.1 \%$ & $43.1 \%$ \\
Occupations usually requiring college or apprenticeship training & $43.9 \%$ & $29.5 \%$ \\
Occupations usually requiring high school & $26.2 \%$ & $7.2 \%$ \\
\hline Occupations usually requiring on-the-job training & $7.8 \%$ & \\
\hline
\end{tabular}

Source: HRSDC (2008).

Finally, among OECD countries, Canada has the highest share of university graduates earning at or below half the median level of earnings (18\% in 2009) (Figure 11). Although the reasons for this are not clear, it may reflect in part relatively poor labour-market outcomes of immigrants, who account for almost one quarter of the adult population and are an important fraction of resident tertiary graduates. Based on the 2006 census, the share of recent immigrants with university degrees was almost twice that of native-born Canadians. Among those aged 25-34, 51\% of immigrants who had arrived in the preceding five years held a university degree, compared to $29 \%$ for the native born. Immigrants also account for half of all doctorate holders in Canada and $40 \%$ of master's graduates. Nonetheless, on aggregate immigrants tend to have higher rates of unemployment and significantly lower earnings than Canadian-born workers, and the earnings gap is even larger for recent immigrants with tertiary education. This limits the relevance 
of comparisons of Canadian outcomes with those of other OECD countries in which immigrants make up a considerably smaller portion of resident tertiary graduates.

Figure 11. Earnings distribution of 25-64 year-olds with university education

2009 or latest available year

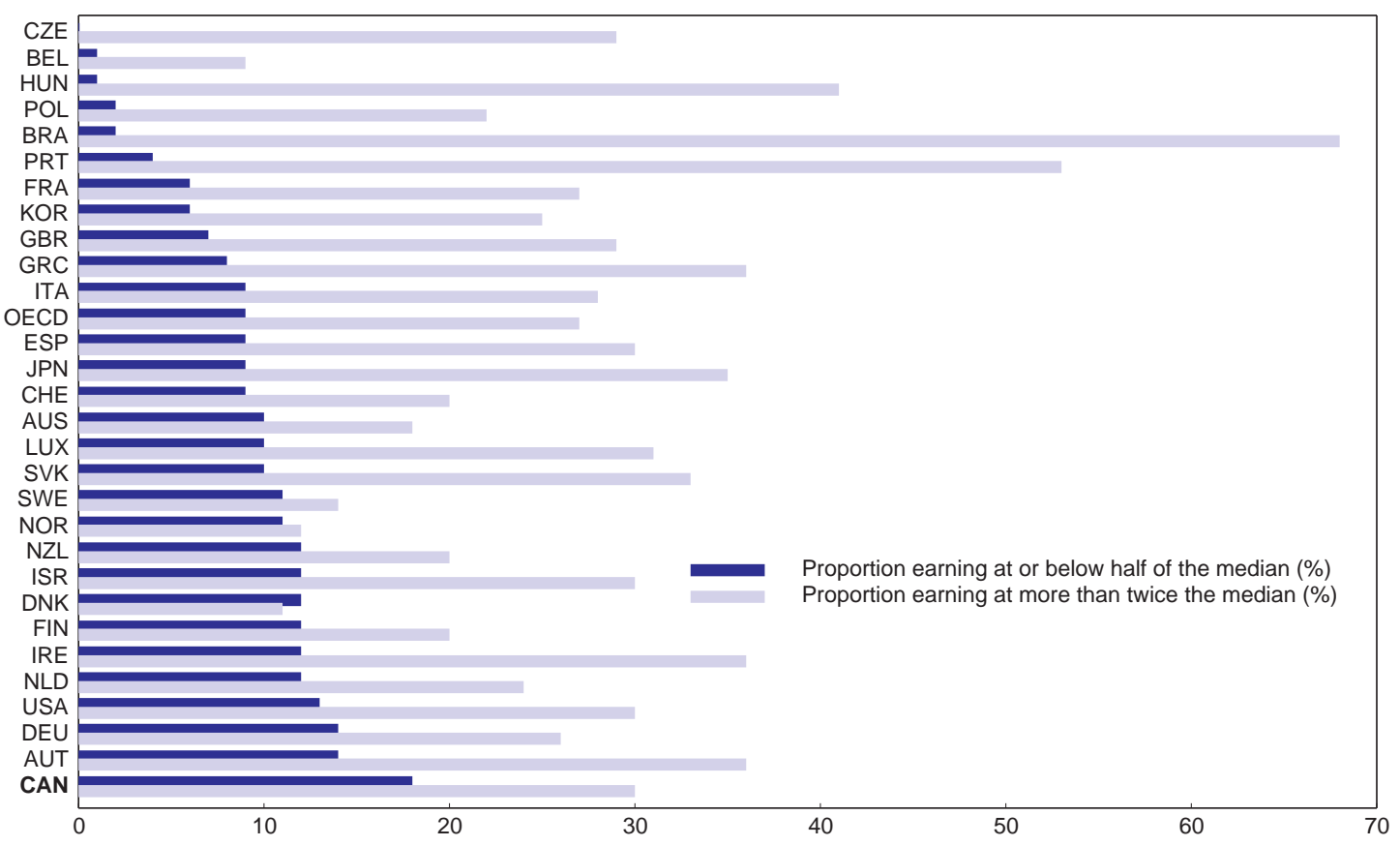

Source: OECD (2011), Education at a Glance 2011, table A8.4

A recent study reveals better labour-market outcomes for immigrants who undertook their post-secondary education in Canada rather than abroad (Rollin, 2011). Pursuing higher education in Canada may facilitate labour-market integration for immigrants (Sweetman and Warman, 2009) by reducing barriers associated with language, social networks and perceived differences in the quality of prior education, while providing access to job-search services. These immigrants also tend to be younger on average than those admitted through the normal immigration system, thus allowing them to contribute to the country's economic prosperity over a longer period of time. Canada has room to expand the number of foreign students it accepts: only $6.5 \%$ of all students in Canadian TEIs were from abroad in 2009, near the OECD average (OECD, 2011a), but that share has fallen from $8.9 \%$ in 2004. Furthermore, Canada hosts only $5 \%$ of the world market for international students (Figure 12), well below the United States $(18 \%)$, the United Kingdom (10\%) and Australia (7\%). While recognising that Canada already receives a high number of international tertiary students (about 170000 in 2010), it is recommended that a greater enrolment of international students in Canadian TEIs be promoted. Such initiatives could be accompanied by continued efforts to expand opportunities for international students to work and obtain permanent residency after graduation, such as the Canadian Experience Class programme introduced in 2008.

Comparatively low earnings of the university educated may also be related in part to measurement discrepancies. A study by Statistics Canada (2009) reported that the outcome largely reflected the earnings of university graduates who were either self-employed or working part-time, whereas many other OECD countries excluded part-time workers from data shown in Figure 11. When considering just full-time 
workers, only $5 \%$ of university graduates and $8 \%$ of college graduates earned less than half the median, placing Canada below the OECD average.

Figure 12. Citizens studying abroad in tertiary education, by country of destination, 2009

Number of foreign students enrolled in tertiary education in a given country of destination as a percentage of all students enrolled abroad, based on head counts

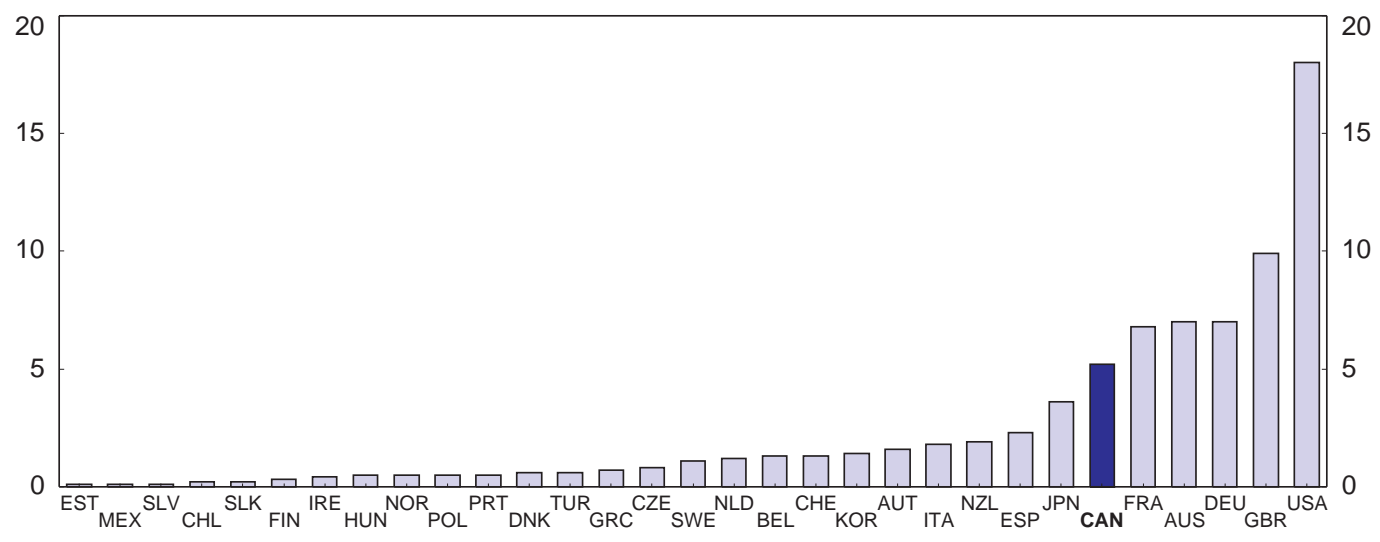

Source: OECD (2011), Education at a Glance 2011, table C3.3.

Returns to university education are found to vary considerably by field and also depend on the availability of jobs in the field of study following graduation. The wage premium for employed university graduates is generally higher in knowledge-intensive industries (Morissette et al., 2004). Graduates from engineering, health, business, mathematics and computer sciences are consistently found to enjoy higher earnings than those from other fields, such as arts and humanities (Stark, 2007; Walters and Frank, 2010). These findings suggest that the labour market continues to place greater value on applied and technical skills than more general skills provided in the liberal arts (Walters and Frank, 2010), where Canada produces comparatively few graduates (Figure 13). The relatively low earnings of Canada's university graduates by international standards may relate in part to the country's lower share of business and computer specialists relative to other OECD countries, combined with a comparatively high share of those studying social and life sciences (who tend to reap lower returns than graduates of other science fields (Stark, 2007)).

Figure 13. Share of university graduates by field

2009

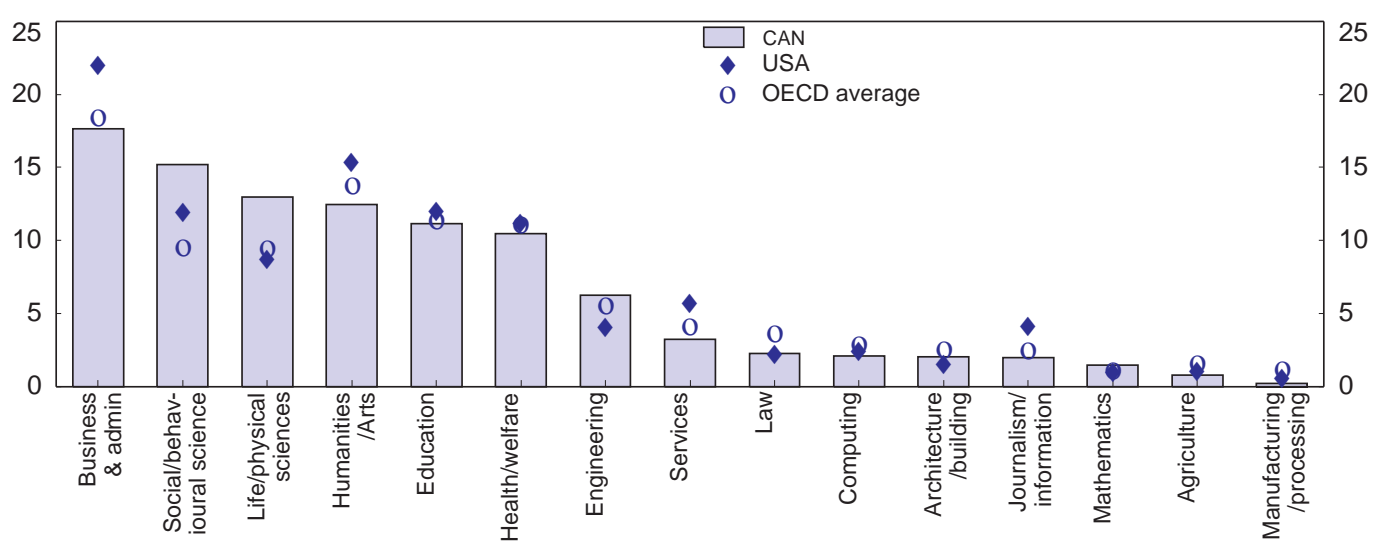

Source: OECD.stat, Education database. 
The value of a liberal arts degree should not be underestimated, however. Despite their earnings disadvantage at any given point in time, liberal arts graduates may enjoy greater long-term employability over their lifetimes compared to those with more vocational training. Whereas very specialised training may act as a limitation during times of rapid structural change, those with more general education may possess stronger skills associated with continuous learning, such as literacy, numeracy and problem-solving. Individuals who lack such foundation skills are less likely to engage in continuous learning and are placed at an economic disadvantage throughout their working lives (OECD, 2011d). Indeed, several studies find that the earnings of liberal arts graduates actually tend to catch up and sometimes surpass those of graduates from applied programmes over time (Giles and Drewes, 2001; Admuti-Trache, 2006).

The monetary benefits of upgrading credentials also depend on the field: for example, using 1996 census data, Stark (2007) finds that men with master's degrees in either engineering or humanities actually earned negative returns compared to those with bachelor's degrees in the same fields. Nevertheless, men with trades certificates have often been found to earn more than their counterparts with community college diplomas (Walters and Frank, 2010), which may reflect skills shortages. Furthermore, doctorate holders in sciences and engineering in Canada tend to have higher rates of unemployment than in many other OECD countries (Auriol, 2010). These outcomes may again reflect the employment challenges faced by immigrants, who constitute half of all PhDs in the country (many of which were earned abroad), more than in most other OECD countries. They may also signal an under-utilisation of science skills in the economy relative to their supply. While the evidence is sometimes mixed, in general studies suggest that the graduates of engineering, computer science, business and health fare much better than graduates of other fields in terms of earnings, employment rates and job-education matches (Drewes, 2010; Walters and Frank, 2010; Yuen, 2010; Boudarbat and Chernoff, 2009)

The variability in labour-market outcomes by field highlights the importance of making information on labour-market conditions for each field of study publicly accessible so that students can make informed decisions about their education and career paths. Various studies (Gunderson and Krashinsky, 2009; Boudarbat, 2004) find that expected earnings and employment prospects factor significantly into the field of study chosen by tertiary students, which may suggest that individuals are generally informed about projected future wages and labour-market opportunities. The federal government regularly conducts a Canadian Occupational Projection exercise to produce a 10-year labour-market outlook. This exercise feeds into Working in Canada, an online career-planning tool that reports a wealth of information on 520 different occupations, including national and regional employment conditions, wages, and skill and educational requirements. Links are also provided to educational programmes that lead to each occupation, as well as Canadian TEIs that offer them. This information is used in education planning by policymakers and TEIs, as well as by students and job seekers, although concerns have been expressed about its timeliness and reliability (Advisory Panel on Labour Market Information, 2009).

Going forward, demographic trends are projected to push the ratio of older, inactive people to workers from $38 \%$ in 2000 to over $70 \%$ in 2050 in OECD countries, with much the same for Canada (OECD, 2006). This means that the demand for skills will continue to expand in the health sector and in services that provide leisure and well-being activities (OECD, 2011d). The federal government's most recent 10-year Canadian Occupational Projection predicts that the retirement of baby boomers will account for $70 \%$ of all job vacancies from 2011 to 2020. During this period, two thirds of all job openings are projected to be in management occupations or in those normally requiring university, college or vocational education. Management and high-skilled occupations in health care, oil and gas, and trade, transport and equipment sectors are expected to experience the most pronounced labour shortages by 2020 .

Labour shortages created by demographic ageing are likely to surface more slowly in the skilled trades, where the average age tends to be younger than for those employed in other occupations 
(Pyper, 2008). As of 2007, the ratio of young workers to near-retirees in the skilled trades was one on average, compared to 0.7 for other occupations (Pyper, 2008). Nonetheless, regional imbalances in the demand and supply for workers in skilled trades have grown as a result of the impacts of both the oil boom in western provinces and the manufacturing bust in Ontario. These adjustment costs are likely to persist in the near term to the extent that skills are not transferable between the two sectors and labour is not fully mobile. The government has taken steps to address such issues by offering training incentives through apprenticeship grants (see Box 4) and by working to harmonise interprovincial standards and certifications for skilled trades through the Red Seal Program and Chapter 7 of the Agreement on Internal Trade.

\section{Supply of innovation skills}

Human capital contributes to innovation through the generation of new knowledge used to create new products and processes, and the empirical literature provides evidence of a positive link between education levels and innovative activity. Higher skill levels raise the economy's capacity to absorb and diffuse new ideas or technologies. Innovation also draws upon a wide range of skills, including domain-specific skills (such as computer science or architecture), thinking and creativity skills (such as problem-solving), as well as social and behavioural skills (such as risk-taking).

There is thus no one level of educational attainment or field of study that is optimal for fostering the skills that drive innovation. Different skill mixes are likely to be required, depending on the stage of the innovation process or the type of innovation that prevails in an economy. According to the model of Vandenbussche et al. (2006), countries close to the world technology frontier such as Canada will see the largest marginal impact on productivity growth come from advanced education, given their higher R\&D intensities (OECD, 2011b). Other countries may engage primarily in adopting existing technologies rather than actual invention, which may instead require a skill set that is best obtained through general education and on-the-job training. Multi-disciplinary skills may also be more important, given the changing nature of innovation, which is increasingly driven by user needs and collaboration across sectors (OECD, 2011b). Furthermore, since innovation is the creative process of putting new ideas into action, it is important that teaching and student assessment practices at all levels of education do not inhibit risk-taking, but rather create an environment for curiosity-driven inquiry.

Canada's relatively high rate of tertiary educational attainment implies a workforce with a solid skill base to adapt to the changing needs of the digital age. As for advanced degrees, however, Canada ranks less favourably with a graduation rate of $9.0 \%$ of all adults for master's degrees and $1.2 \%$ for $\mathrm{PhDs}$ in 2008 (compared to OECD averages of $12.7 \%$ and $1.5 \%$, respectively) (OECD, 2011a). This may reflect in part low demand for advanced skills in the labour market. For example, a survey of over 1000 Canadian R\&D-performing firms for the Review of Federal Support to R\&D (2011) revealed that only $18 \%$ of such firms reported employing researchers with doctoral degrees. Canadian businesses also employ a smaller share of PhDs than their US counterparts, which the Council of Canadian Academies (2009) attributes to lower business demand for advanced research skills.

Canada appears to also fall short in supplying business skills. Although business graduates account for the largest proportion of all university degrees awarded (17.7\%), they represent even larger shares in the United States (at 22\%) and in other OECD countries (an average of 18.4\%). A significant body of empirical work finds that the quality of management and leadership heavily influences the adoption of continuous innovation strategies and the effective use of knowledge and technology. Even if it is not clear whether such skills are inherent versus learned, it is becoming commonly accepted that managerial and entrepreneurial skills should be part of education curricula from an early stage (OECD, 2011b). Entrepreneurship training should also closely involve the business community through student interactions with local entrepreneurs and internships with start-up companies (OECD, 2010b). At Canadian firms, managers and leaders tend to be less educated than their US counterparts - fewer managers and CEOs in 
Canada possess a university degree or MBA than south of the border (Institute for Competitiveness and Prosperity, 2009). This managerial education gap is widest in small and medium-sized enterprises, which are also found to be slower to adopt new advanced technologies than those in the United States (Sharpe, 2005). The Council of Canadian Academies (2009) argued that this lower level of business education may lead to less effective management practices and generally weaker business demand for innovation in Canada.

Canada scores relatively well in the sciences, technology, engineering and maths (STEM) fields, where its proportion of tertiary graduates exceeds both the OECD average and that of the United States (Figure 13 above). These shares also increased over the 1998-2009 period (with the exception of maths, which saw a slight dip from $1.6 \%$ to $1.4 \%$ ). Although Canada has a low share of PhDs by international standards, $54 \%$ of its doctorate degrees awarded in 2008 were in science and engineering, placing it fourth highest among a sample of 38 OECD and emerging market economies (Figure 14). Canada also has a higher-than-average share of researchers in total employment $(8.6 \%)$, but a below-average share of the workforce in science and technology occupations (30\%) (OECD, 2011c). Women tend to be underrepresented in the STEM fields, however, as in other OECD countries. In an effort to strengthen human capital in STEM fields, the 2011 federal budget announced that HRSDC would reallocate CAD 60 million over three years to fund the development of "digital skills" among youth and Aboriginal groups, and to promote enrolment in key disciplines such as STEM disciplines.

Skills shortages have nevertheless been reported in information and communications technology (ICT) occupations, which are expected to persist in the medium term, according to the Information and Communications Technology Council (2008). This shortage is related not to an under-supply of individuals with the necessary educational qualifications, but rather to a lack of graduates possessing the right "package" of core technical skills, industry experience, communications skills and business acumen that is increasingly sought by employers. It is believed that the lack of practical and business components in computer science courses has damaged the employability of graduates, causing university and college enrolments in this field to decline since 2001. This imbalance would best be addressed by expanding the offerings of tertiary programmes that integrate ICT with business and communications elements, while strengthening academic-industry links to increase internship and co-op opportunities within these studies. While many colleges have made advances in this area, progress has been slower at universities.

Figure 14. Science and engineering graduates at doctorate levels, 20091

As a percentage of all new degrees awarded at doctorate level

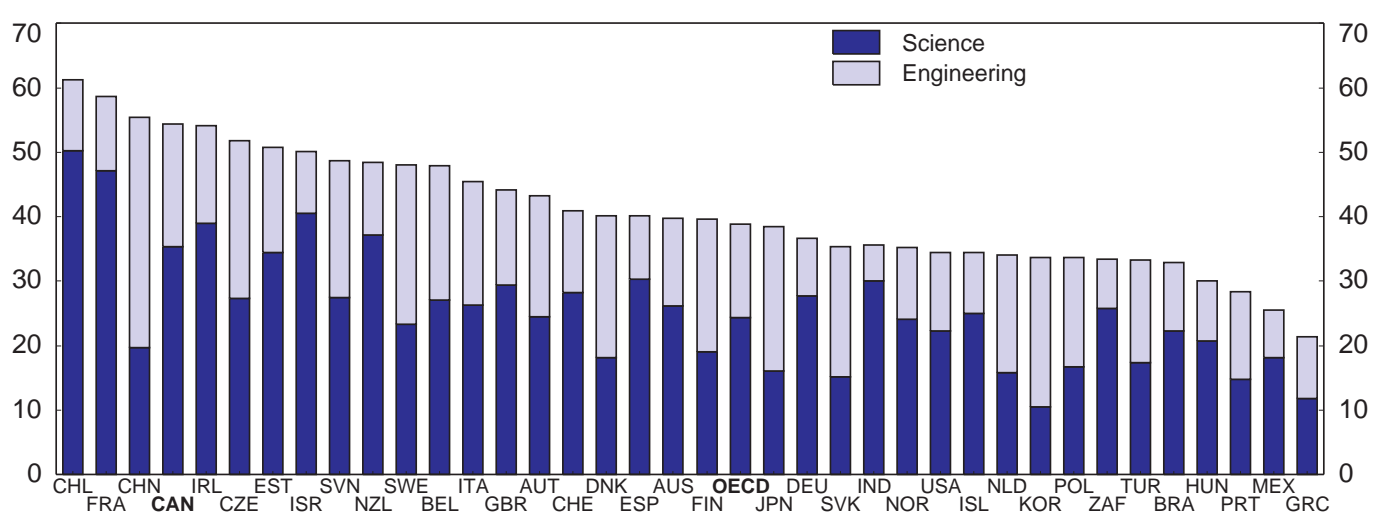

1. Or latest available year.

Source: OECD (2011), OECD Science, Technology and Industry Scoreboard 2011. 


\section{The higher education system: aligning institutional incentives with policy priorities}

From governments' perspective, the ultimate goal of education policy is to ensure that public resources are spent efficiently on a system that is meeting the broad social and economic objectives of the country. A number of widely accepted economic objectives are to produce a skilled, adaptable and inclusive workforce able to meet the country's labour-market needs and to create knowledge and innovation that feeds into business and community development. Globalisation has also raised the importance of having the tertiary system contribute to the country's international competitiveness.

\section{Financing tertiary education institutions}

The capacity of TEIs to produce high-quality education clearly depends in part on the amount of funding available to them. Canada devotes a relatively large share of its GDP to tertiary education by OECD standards at some 2.5\% (Figure 15, Panel A). By 2007, TEIs received average total funding of about CAD 20000 per student (Panel B), up moderately since 2000 (Panel C), with increases observed in

Figure 15. Funding to tertiary education
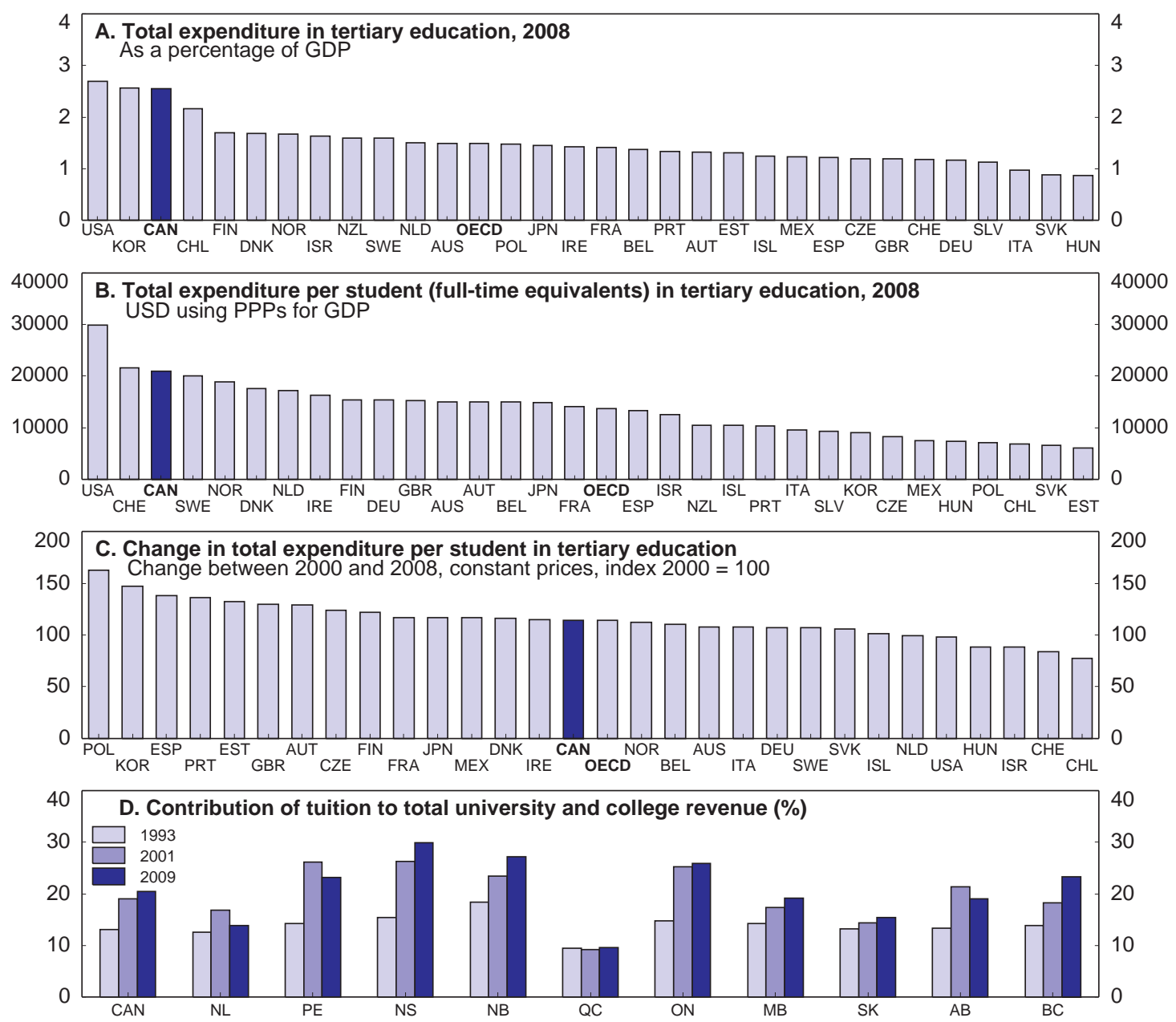

Source: Statistics Canada and OECD (2011), Education at a Glance 2011, tables B6.1, B1.5 and B1.1a. For Canada, the reference year is 2007 . 
all provinces. Both public and private expenditure shares exceed the OECD average (Figure 16). Governments generally fund the provision of tertiary education because of market failures associated with capital markets, imperfect information and positive externalities. Externalities identified in the literature include: greater innovation leading to faster income gains, reduced crime rates, and improved health outcomes and civic engagement. However, the ample evidence that individuals enjoy substantial private benefits to higher education argues in favour of sharing the cost of provision between governments and students, and indeed tuition represents 10 to $30 \%$ of total TEI revenues, depending on the province (Figure 15, Panel D); that share has been rising over time in most provinces. Direct public funding accounts for $59 \%$ of total TEI revenues, compared to an OECD average of $69 \%$. Household expenditures account for $20 \%$, also below the OECD average of $25 \%$, whereas other private entities (such as private donors and enterprises) contribute a comparatively high share of 21\% (Table B3.2 in OECD (2011a)).

Figure 16. Expenditure on tertiary education institutions

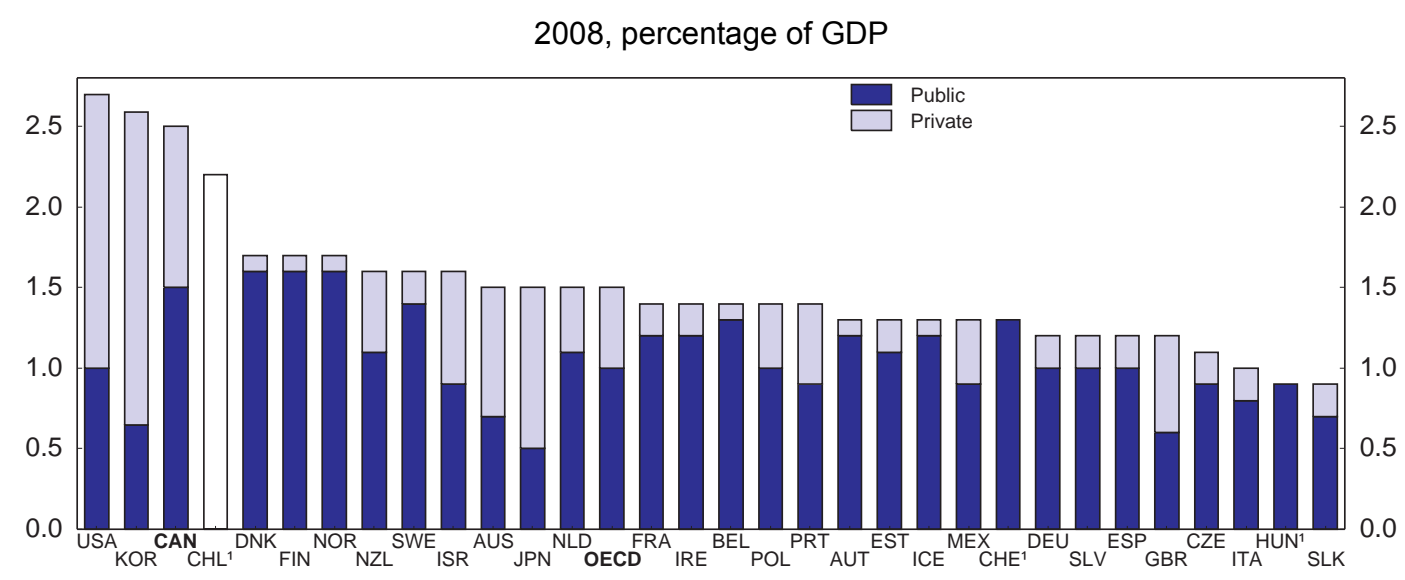

1. Total expenditure for Chile; only public expenditure for Hungary and Switzerland. For Canada, the reference year is 2007.

Source: OECD (2011), Education at Glance 2011, table B2.3.

Levels of public funding should ideally be set to reflect the magnitude of externalities relative to private benefits (Santiago et al., 2008), although it is difficult to quantify the value of non-monetary social benefits such as stronger communities or greater overall life satisfaction. However, OECD (2011a) provides estimates of both public and private monetary rates of return per individual obtaining tertiary education using a net present value approach based on investment theory. This approach generates an efficiency measure of the decision to invest in tertiary education and is to be distinguished from the earnings-function method (Mincer, 1974), which estimates the contribution of education to gross earnings while controlling for other factors. The private rates of return incorporate the benefits of higher after-tax lifetime earnings and lower unemployment rates relative to secondary school graduates, net of costs such as tuition and foregone wages during studies. The public rate of return is derived from the benefits of increased future tax receipts net of the cost of direct expenditures on TEIs and student aid. These estimates suggest that the public internal rate of return on investment for an individual obtaining tertiary education in Canada is $9-11 \%$ per year, while the private rate of return is $11-12 \%$; both are close to their respective OECD averages $(\mathrm{OECD}, 2011 \mathrm{a})$. The ratio of public to private rates of return can be viewed as a measure of the degree of public subsidisation of tertiary education (Psacharopoulos, 2008). These estimates are necessarily rough and do not take into account its full public financial costs and benefits.

There are, however, wide variations across the country in the extent to which students share the cost of tertiary education. The share of tuition in total college and university revenues ranged from $10 \%$ in Québec to 30\% in Nova Scotia in 2009 (Figure 15, Panel D). These numbers overestimate the student share 
of the cost of tertiary education, since they do not take into account government subsidies provided directly to students to offset their costs. From the early 1990s to 2009, the share of tuition funding in total revenues of TEIs increased in all provinces except Québec, on average by about half. These variations reflect different provincial tuition policies over time: tuition declines were imposed in Manitoba, and Newfoundland and Labrador, in the early 2000s, while other provinces have implemented tuition freezes at various times during the last two decades. Québec has had the longest tradition of keeping tuition levels low. A provincial parliamentary committee noted in the early 2000s that Québec universities were less competitive as a result of chronic underfunding compared to other Canadian universities, which it considered to be related to the province's tuition policy. Although recent policy changes will increase the student contribution over the next five years (see Box 3), the resulting average undergraduate tuition by 2016-17 (about CAD 3820 in nominal terms) will remain considerably below the 2011-12 country-wide average of CAD 5370.

With the exception of Québec, caps on tuition increases generally exclude international students as well as professional programmes such as law, medicine, dentistry and business. Such fee differentiation can be advantageous in that it reflects costs and facilitates more equitable cost sharing, with greater contributions from those expected to reap the largest private returns to their studies. Policies that keep tuition levels fixed at a low level may also erode institutional incentives to improve quality by, for example, competing for the best professors, while weakening student incentives to successfully complete their studies in a timely fashion. More generally, stronger price signals can improve efficiency in tertiary education by making the system more responsive to student and labour-market demands. Such an outcome is conditional, however, on having undistorted labour markets and students who are well informed about the costs, quality and future income prospects of each field of study.

However, complete deregulation of tuition fees would subject public costs to the unpredictability of institutional pricing strategies, particularly if governments wish to maintain access for disadvantaged groups through non-repayable grants to cover the cost of tertiary studies. Striking the right balance could therefore involve allowing tuition fees to evolve in line with household income levels or a cost index such as the Higher Education Price Index, used in the United States and the United Kingdom, while ensuring that student financial-aid policies are correspondingly adjusted to ensure low-income students are not adversely affected.

\section{The impact of public funding strategies}

Because the financing of higher education is shared among provincial governments, the federal government, students and industry, TEIs are accountable for meeting the needs of a variety of "clients", whose objectives and priorities may differ substantially. With governments contributing the largest share to revenues, the design of public funding mechanisms can greatly influence the incentives of TEIs. In general, public funding mechanisms should be designed in such a way as to steer institutions' incentives to meet policy priorities, for example with respect to access, quality, efficiency and responsiveness (Santiago et al., 2008). Funding strategies should, however, allow TEIs to remain sufficiently empowered to innovate and take their own initiatives to improve quality. The general aim of policy is to create conditions for a sustainable and coherent system of diverse, high-quality TEIs responsive to external demands and accountable for the outcomes they produce. Federal and provincial governments also need to coordinate their funding strategies to maximise the effectiveness and complementarity of their contributions.

Government support and tuition fees account for $90 \%$ of university operating and special purpose funds, which finance the primary activities of teaching, core (unsponsored) research and student support services. During the 1990s, fiscal restraint combined with regulated tuition fees significantly reduced growth in general operating expenditures of TEIs, and the number of full-time university faculty declined 
by $10 \%$ from 1992 to 1998 (AUCC, 2011). Between 2000 and 2008, provincial operating funding to universities rebounded, in large part to support a substantial increase in student enrolment. Surging student populations from 1998 onwards reflected in large part the "echo boom" generation (the offspring of baby boomers). A number of larger universities have recently begun to address funding shortfalls through greater foreign-student enrolment, since international student fees are not subject to regulation in most jurisdictions.

Provinces provide TEIs with operational support primarily through either incremental funding or formula funding mechanisms. Incremental (or block) funding determines the amount allocated to each institution based on historical amounts provided plus some percentage increase. Under formula funding, the amount allocated depends on institutional characteristics such as student population, programme mix and campus locations. Both types of funding offer desirable features in the form of transparency and predictability, which allow TEIs to implement long-term strategic planning. However, historically based block funding creates no meaningful incentives to improve quality or efficiency. To the extent that formula funding rewards TEIs for enrolment, it may generate incentives to create innovative programmes or improve teaching quality to attract students. However, formula funding may also introduce distortions, for example by encouraging TEIs to shift admission rates in favour of lower-cost programmes to improve finances (Pakravan, 2006).

\section{Targeted funding mechanisms}

Across OECD countries, a trend has been observed towards allocating public funds through greater targeting, performance-based funding, competitive mechanisms and expanded student-support systems (Santiago et al., 2008). Public funding for tertiary education in Canada has evolved in a similar fashion since the early 1990s, which has had an important influence on institutional incentives. For example, financing for student assistance and targeted research grants has increased considerably since the late 1990s. Provincial governments have also earmarked an increasing share of operating funds for specific purposes in an attempt to influence institutional incentives to meet certain policy objectives or improve performance (Snowdon, 2005). For example, certain provinces have legislated requirements that allocate a portion of tuition increases for student financial assistance, while some have used "performance-based" or "outcomes-based" funding. The latter approach allots a specific amount of provincial funding to TEIs conditional on the achievement of various outcomes.

A number of provincial governments also allocate a portion of tertiary investments through strategic funding to expand spaces or provide scholarships in areas of high priority or labour-market shortage, such as science and technology or nursing. While such strategies may promote enrolment in these fields, they do not guarantee that graduates will seek employment in related occupations if labour-market signals do not function properly. For instance, wages in science and technology-intensive sectors may not adequately capture the wider societal benefits associated with innovation, leading the private sector to under-value those skills. Furthermore, international experience shows that attempts to expand enrolment in specific fields in contradiction to wage signals often lead to an oversupply of graduates who then seek employment outside of the country or in other fields (Santiago et al., 2008). A more effective approach may be to use demand-side measures such as loan waivers for students who enter such occupations (Santiago et al., 2008).

\section{Strengthening the tertiary education sector's contribution to innovation}

The tertiary education sector can contribute to the economy's innovative performance through two main avenues: research and skills formation. Since 1998, the federal government has introduced a number of strategic initiatives to strengthen the country's capacity for research and innovation (Box 5). Through the three federal granting councils, sponsored research funds more than doubled from 2000 to 2010 
(AUCC, 2011). Provincial and territorial governments have also been increasingly active in supporting research and innovation. The nature of recent research funding initiatives has also created incentives to shift institutional resources towards research projects with some commercial value or industry application, and many universities now commonly employ offices for technology transfer and industry liaison. While this may allow academic research to provide a more valuable contribution to the country's innovation performance, it has also generated concerns among parts of the academic community over the potential ramifications for basic research activities.

\section{Box 5. Initiatives to support research and innovation}

Federal, provincial and territorial governments are active in supporting research and innovation. The three federal granting agencies - the Natural Sciences and Engineering Research Council (NSERC), the Social Sciences and Humanities Research Council (SSHRC) and the Canadian Institute of Health Research (CIHR) - together provide the largest source of external funding to TEI research programmes and scholarships for graduate students and postdoctoral researchers. In recent years, the federal government has also introduced a number of major initiatives to strengthen the environment for research and innovation in Canada, including:

- $\quad$ Canada Foundation for Innovation (CFI): established by the federal government in 1997, the CFI funds infrastructure costs for research projects in Canadian universities, colleges, research hospitals and non-profit research institutions. The CFI provides up to $40 \%$ of funding, with the balance covered by institutions and their funding partners. The 2012 budget provided an extra CAD 500 million over five years.

- Canada Research Chairs programme: created in 2000, it provides funding of CAD 200000 annually for seven years to 1000 Tier-1 chairs selected for outstanding research contributions, and CAD 100000 annually for five years to 1000 Tier-2 chairs with exceptional emerging research potential. Institutions submit nominations based on strategic research plans, which are then assessed by international experts.

- Indirect Costs programme: introduced in 2003, it provides annual grants to universities and colleges to help fund a portion of indirect institutional costs of federally funded research projects, including costs such as maintaining facilities, ensuring regulatory and safety compliance, and managing intellectual property.

- Centres of Excellence in Commercialisation and Research programme (CECR): launched in 2007, it is investing CAD 285 million over five years in centres to advance research and assist the commercialisation of new technologies, products and services within four priority areas of the federal government's science and technology strategy: environment, natural resources and energy, health and life sciences, and information and communications technologies. CECR funds must be matched by industrial partners.

- $\quad$ Canada Excellence Research Chairs (CERC): created in 2008 to award world-renowned researchers and their teams up to CAD 10 million over seven years to establish research programmes at Canadian universities. Chairs are selected through a rigorous peer-review process in the four priority areas of the federal government's science and technology strategy.

Provincial and territorial governments have also been increasingly active in supporting research and innovation. Selected examples include: the Leading Edge Endowment Fund (LEEF) in British Columbia, which attracts world-class researchers to the province; the Ontario Centres for Excellence, which foster the training and development of the next generation of innovators and entrepreneurs; the Manitoba Research and Innovation Fund (MRIF), which provides funding for provincial research and innovation; and Alberta Innovates, which consists of four corporations that co-ordinate efforts and resources in key areas where Alberta has a competitive advantage.

Because external grants cover only a portion of the cost of designated research projects and some federal grants require matching provincial contributions, provincial governments have also increased direct support for sponsored research. Universities have furthermore had to draw upon general operating funds to cover the related unfunded costs when their faculty succeed in procuring research grants. Although the Indirect Costs programme was introduced to address this issue (Box 5), an independent evaluation conducted in its sixth year of operation reported that the amounts provided were insufficient to cover the institutional costs of research, particularly for research-intensive universities (Circum Network and 
Malatest, 2009). Such costs include operating and maintaining research facilities, ensuring regulatory and safety compliance, managing intellectual property and developing capacity for technology transfer and industry liaison.

The shift in public funding away from core operating activities towards targeted research appears to have increased the quality of research in the tertiary sector. By 2010 , higher education accounted for $38 \%$ of the country's total R\&D activity, up from $27 \%$ in 1998. Between 2000 and 2007, the number of scientific articles per million population increased from 745 to 844, placing Canada in the world's top ten. The various federal research funding initiatives are likely to lead to a greater contribution by TEIs to the innovation performance of the economy, while also strengthening the development of advanced skills among graduate students supported by research grant recipients.

The development of innovation skills could be further enhanced by modifying curricula to ensure that STEM, ICT and other technically oriented programmes fully integrate elements of communication, business and entrepreneurial training. This could be accomplished through review processes within provincial quality-assurance frameworks (Box 6). For example, the province of Ontario is developing benchmarks for degree-level expectations and learning outcomes by field of study, to be used to approve new programmes and evaluate existing ones during periodic reviews. Student assessment practices should also be included in these reviews to ensure students are being evaluated on higher-order thinking skills and not just content. Expanding cross-disciplinary programmes combining arts fields with business education should also be encouraged.

\section{Box 6. The quality-assurance framework for higher education in Canada}

In Canada the provinces and territories are responsible for their own educational systems, therefore no single pan-Canadian body exists to quality assure TEls or programmes. In 2007 a degree-level standards framework was endorsed through the Council of Ministers of Education, Canada (CMEC) by provincial and territorial ministers to provide guidance on quality assurance and learning outcomes for all bachelor's, master's and doctoral degrees. In practice, quality assurance of degree-granting institutions generally involves adherence to provincial requirements enunciated within legislation while respecting TEls' autonomy. Ontario, Alberta and British Columbia have established external quality assurance boards and agencies to review TEls' new programme proposals. Prince Edward Island, Nova Scotia and New Brunswick have agreed to a degree-level Qualifications Framework under the aegis of the Maritime Provinces Higher Education Commission. In Québec all undergraduate and graduate programmes undergo quality review through the Conférence des recteurs et des principaux des universités du Québec's (CREPUQ)'s New Program Evaluation Commission (CEP), which assesses the quality of undergraduate, graduate and doctoral study programmes. In Manitoba the Council on Postsecondary Education is responsible for programme approval.

Certain professional programmes at the tertiary level are accredited by external agencies, which are recognised by or associated with regulatory professions that are responsible by law for licensing certain professionals in the provinces and territories. Quality assurance in the trades and apprenticeship programmes usually centres around the Red Seal designation, which facilitates mobility between provinces and territories and which requires passing standardised inter-provincial examinations developed in association with the Canadian Council of Directors of Apprenticeship who represent the provinces and territories.

A potential consequence of raising the amount of research funding that is allocated on a competitive basis is that scientific research may become increasingly concentrated on fewer "star" academics who receive larger grants. Whereas previously research grants were awarded in smaller amounts to a larger number of recipients, the recent changes aim to target funds where the impact on knowledge creation and innovation is likely to be greatest. The result may be a concentration of grants to large universities with big laboratories, forcing other institutions to become primarily teaching universities. Such a result would increase the degree of differentiation among Canadian universities, moving the system closer towards that observed in the United Kingdom or the United States (Vajoczki et al., 2011). 


\section{Fostering a high-quality system}

\section{Greater institutional differentiation could improve quality and efficiency}

Creating a formal distinction between TEIs that engage in research and those that emphasise teaching may help promote overall quality and competitiveness by concentrating institutional resources where comparative advantages exist. In the current environment of rapid enrolment growth and constrained public funding, a possible cost of the expansion of faculty research incentives over the last several years has been in the time spent teaching the broader student population. Between 1992-93 and 2008-09, swelling enrolments boosted the ratio of full-time students to full-time teaching staff at universities (Figure 17), most notably in British Columbia (from 14 to 23) and in Ontario (from 16 to 23). Many professors in Ontario report allocating more time to research than teaching, based on perceptions that this would improve their chances for tenure and promotion (OCUFA, 2008). Moreover, the average pay for full-time Canadian university teachers seems rather high on an international comparison (Altbach et al., 2012). As a result, more undergraduate courses are now being taught by temporary lecturers ("sessionals"), who constitute over one-quarter of full-time teaching staff in some universities (CAUT, 2011).

Figure 17. Ratio of university full-time students to full-time teaching staff

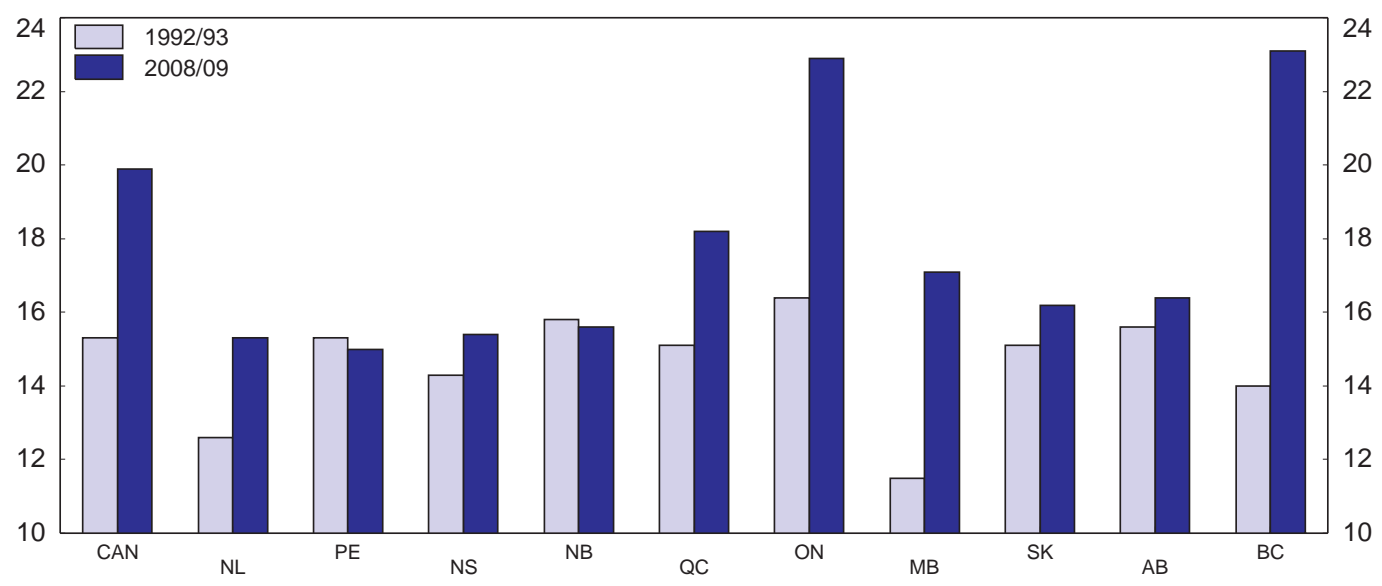

Source: Statistics Canada.

These trends have raised concerns that the quality of undergraduate education has declined, at least in certain provinces (see for example, AUCC, 2011 and Clark et al., 2010). High student-teacher ratios may reduce student engagement and necessitate different assessment methods, for example favouring multiple-choice testing rather than open-ended writing assignments, which may limit the development of higher-order skills such as critical thinking and reasoning (Looney, 2009). Contract instructors may teach few classes, and receive lower wages with little job security, leading to limited institutional commitment and campus presence to engage with students beyond classroom hours (Farr, 2008). Teaching quality is, however, difficult to measure and observe in practice. There is furthermore little hard evidence proving that the quality of undergraduate instruction has fallen over time, given generally good labour-market outcomes of university graduates and favourable student evaluations.

Formally designating universities to be either research- or teaching-focussed may improve accountability by clarifying the public's expectations for institutions' outcomes and their criteria for quality assessment (Weingarten and Deller, 2010). However, it is not clear whether increasing the separation between the research and teaching functions of universities would affect student learning. The correlation between faculty research output and quality of instruction is not well established; studies based 
on student satisfaction surveys find an inverse relationship between research productivity and teaching quality, while others suggest that research positively affects teaching, but that teaching adversely affects research (Vajoczki et al., 2011).

Student choice and overall quality of tertiary education could also be enhanced by encouraging greater institutional competition. This could be promoted by recognising new types of institutions, including greater openness to the establishment of private universities, which exist to a very limited extent and only in British Columbia, apart from religiously affiliated or exclusively online institutions.

\section{Funding based on performance}

Continuing to provide a substantial proportion of public support to TEIs through formula funding can provide benefits in the form of autonomy, stability and predictability that allow them to engage in strategic long-term planning. Additionally, allocating some portion of core funding to TEIs based on performance can be a useful tool to align incentives with policy priorities. However, whereas quantifiable outputs permit the systematic evaluation of research quality, assessing performance in teaching is less straightforward.

Use of performance-based or outcomes-based funding has thus far had limited success in driving institutional improvements in Canada. In many provinces, publicly funded colleges and universities must collect and report data that are common and comparable across institutions, such as Ontario's key performance indicators (KPIs). Performance indicators can include measures of student retention, graduation, employment, graduate satisfaction, student-loan default and access for under-represented groups. Provinces vary in the way they use these data, and only a few (Alberta, Ontario and Québec) have ever tied even a small fraction of TEI funding to the outcomes they measure; Ontario is the only one that still does so. However, the conditional funding provided has been too limited to finance improvements, with the end result being less predictability and stability of TEI funding, combined with more reporting requirements (Snowdon, 2005). Meanwhile, Québec has introduced "performance commitments", which formally designate all tuition and public funding increases to universities between 2012-13 and 2016-17 to meet objectives based on the attainment of 13 target indicators (Finances Québec, 2011). Such funding mechanisms normally form part of an overall quality-assurance framework (Box 6).

Performance-based funding needs to be carefully implemented and the indicators designed in such a way to avoid generating perverse incentives (Santiago et al., 2008). Although performance indicators such as the KPIs can provide useful information both for institutions to gauge progress or identify weaknesses and for students to make decisions about their educational paths, they are crude measures. Many of the outcomes they measure, such as graduation rates or employment rates, may be highly correlated with the initial characteristics of students entering the particular institution and do not necessarily reflect the quality of education provided.

Tying significant financial rewards or penalties to institutions' performance on a set of crude indicators may stifle the risk-taking and intrinsic motivation necessary for innovation. It may encourage instructors to emphasise student outputs that are easily observable, while neglecting the development of less measurable but important skills such as creativity (Santiago et al., 2008). For example, linking funding to graduate employment rates may generate short-sighted incentives to limit student enrolments in fields with lower immediate employment prospects. The selected indicators should measure only those outcomes for which it is appropriate to hold institutions accountable and may vary with each institution based on its declared goals. While it is reasonable to expect certain professional, technical or vocational programmes to ensure graduates are employable in their field of study, it is equally important for tertiary education to provide broader intellectual development and foster the wide range of skills needed for innovation and good citizenship. As technologies change and skills become outdated at a faster pace, graduates may work in a number of different fields over their careers that do not necessarily correspond to their initial training. 
Proficiency in many skills needed for innovation (such as creativity) cannot be easily assessed through an indicator or large-scale standardised tests.

Given such shortcomings, the use of performance-based funding in Canada should be expanded only if an improved set of indicators can be developed. Part of the challenge relates to poor data availability and more broadly a lack of system-wide data linking student outcomes to indicators of institutional quality that are comparable across provinces or even institutions, although some provinces such as British Columbia appear to have made encouraging advances in this dimension. This creates obstacles for students to make informed decisions about their education and career paths, as well as for governments to demonstrate accountability for public funds. While institutional rankings exist (for example, the annual Maclean's University Rankings and Shanghai-based Academic Ranking of World Universities), these normally focus on input or output measures, which may depend heavily on the amount of resources available to the institution or initial characteristics of entering students. Competing views about the purpose of higher education can also complicate the assessment of quality.

Rather than assessing performance based on a set of outcomes, Finnie and Usher (2005) emphasise that quality should be measured by the "value added" institutions contribute to achieving their stated objectives. Their approach recognises that educational outputs are closely correlated to inputs (such as teaching salaries or library resources) as well as the initial student characteristics, and institutions should be rewarded based on the impact they have on outcomes such as student learning. Assessing value added would entail estimating how different educational inputs affect learning outcomes, while controlling for students' beginning characteristics, in order to identify and quantify what types of inputs are associated with high quality (Finnie and Usher, 2005). Funding could then be awarded to institutions that utilise such desirable inputs.

The set of performance indicators used could also be widened to include measures of student learning. Since no single indicator offers a comprehensive, exact measure, it would be necessary to consider a number of different sources. Statistics Canada's National Graduates Survey has provided useful information on short- to medium-term labour-market outcomes of graduates from public universities, community colleges, and trade or vocational programmes; however, they are conducted on an irregular basis, most recently in 2007, and ongoing funding may be affected by current financial constraints. The highly successful National Survey of Student Engagement (NSSE) and Community College Survey of Student Engagement (CCSSE) provide precise and quantitative data on student learning experiences that can be compared across institutions. ${ }^{6}$ While over 80 Canadian universities have taken part in NSSE on a voluntary and irregular basis, participation could be expanded and made a requirement for eligibility to receive such performance-based funding. Another promising avenue for the future is the OECD's international Assessment of Higher Learning Outcomes (AHELO), which is currently in development (with the province of Ontario among the participants) and aims to evaluate the capacity of final-year bachelor's degree students to use, apply and act on their knowledge and reasoning.

Labour-market responsiveness could be encouraged by using public funding to reward tertiary institutions based on student placements in co-op or internship posts, and to encourage career-guidance services. Co-op and internship opportunities can provide valuable practical training for the workplace that may enhance student learning, while allowing institutions to strengthen industry linkages through

6. Originated in the United States, these simple surveys ask students a number of questions (including frequency of contact with faculty, average frequency and duration of homework, etc.), and results are converted into a score which measures the average learning experience acquired at an institution (Finnie and Usher, 2005). 
technology transfers. ${ }^{7}$ The prominent co-op programme at the University of Waterloo, for example, has been credited with helping to create the hi-tech innovation cluster that has developed around the campus (Crocker and Usher, 2006). Employer feedback on student performance can furthermore provide guidance to TEIs on skills sought by industry, which can be used to adapt programme curricula. Whereas co-op and internship programmes are well integrated into the curricula of most community colleges and polytechnics, they are not widespread across university campuses. Incentives to tap student resources should also proceed from the business demand side, for example through vouchers for academic research (OECD, 2012, Chapter 1).

\section{Greater co-ordination would strengthen overall performance}

Overall, strengthening the quality of the system will require greater funding to co-ordinate data collection on TEIs and student outcomes at a nation-wide level, to ensure comparability across regions. As discussed earlier, these are areas that face considerable implementation challenges due to the decentralised nature of the system, and should thus be coordinated through Statistics Canada, working in partnership with CMEC through the Canadian Education Statistics Council.

Promoting the international competitiveness of the system would also benefit from greater coordination across jurisdictions. In recent years, Canadian TEIs have recognised the importance of internationalisation by developing partnerships with their foreign counterparts, establishing foreign campuses, increasing global research collaboration and faculty and student exchanges, and promoting the "Education in/au Canada" brand to international students. In 2010, provincial and territorial premiers, acting through the Council of the Federation, released an international education marketing action plan that had been prepared by CMEC in collaboration with provincial and territorial ministers of immigration (CMEC, 2011). In 2011, the federal government announced funding and appointed an advisory panel to develop an international education strategy. Canada sends a high proportion of tertiary students to study abroad compared to its peers (UNESCO, 2011) but could stand to benefit from accepting more international students, as discussed earlier. To improve the global visibility of the country's higher education system, it will be important to improve the interface for foreign students so they can navigate easily through the education information offered by the different governments and institutions, while coordinating with Citizenship and Immigration Canada to ensure immigration programmes allow space for foreign students wishing to remain in the country after graduation.

The current system of heterogeneous provincial strategies and policies, combined with the patchwork of information available on the system's quality and performance, may hinder the country's ability to stay competitive and adapt quickly to changing global trends. Making greater use of CMEC intergovernmental body could help tackle the unique challenges of a system governed by 13 different jurisdictions, particularly for: $i$ ) establishing a set of common system priorities and providing leadership to meet policy objectives; ii) collecting and reporting data on TEIs across Canada; iii) establishing a national academic credit registry to coordinate credit transfers and facilitate inter-provincial student mobility; iv) co-ordinating federal and provincial funding strategies to meet common objectives and ensure consistency; and $v$ ) designing a comprehensive internationalisation strategy to strengthen policy coherence across education and immigration authorities, such as through CMEC (2011).

7. Co-op postings are normally full-time paid arrangements that often extend over three work terms alternated with school terms. Internships are typically one-time assignments that may be part time or full time, and paid or unpaid. 


\section{Box 7. Policy recommendations for improving tertiary education}

\section{Improve access for disadvantaged and under-represented groups}

- Increase targeted need-based financial assistance, which may be funded through reduced education tax credits where public finances are constrained. Consider moving fully to an income-contingent student loan repayment system if high initial costs are not prohibitive. Re-evaluate student aid limits to ensure they realistically address the costs faced by students, in particular those with dependents. Reduce barriers for debt-averse financially disadvantaged students by changing the aid application process to separate loans from grants. Consider greater targeting of financial assistance programmes on students with no family history of higher education. Further, reduce barriers for risk- and debt-averse students by providing relevant and reliable information to support their learning and career choices.

\section{Enhance responsiveness of the tertiary system to changing student and labour-market needs}

- Attract a greater share of foreign students in the tertiary education system, and expand opportunities for them to work and obtain permanent residency after graduation.

- $\quad$ Promote a more flexible delivery model of higher education to encourage skills upgrading through continued efforts to strengthen credit-transfer arrangements across TEls (both within provinces and between them), and greater integration and recognition of online and distance learning resources as well as apprenticeship training.

\section{Align institutional incentives with policy priorities}

- In provinces with constrained public finances, evaluate whether tuition policies undermine institutional quality and competitiveness. Consider using fee differentiation by programme or allowing tuition levels to evolve in step with increases in household income or an appropriate education cost index.

- Consider implementing, according to the particular needs and priorities of each province or territory, greater differentiation between institutions that engage in research and those that focus primarily on teaching so as to promote greater quality and efficiency based on comparative advantage.

- $\quad$ Allocate more funding to Statistics Canada to co-ordinate data collection on TEls and student outcomes at a nation-wide level. Undertake efforts to develop a better set of indicators upon which to base performance funding to institutions. Use a value-added approach to select indicators more closely linked to institutions' impact on student learning. Use public funding to reward tertiary institutions based on student placements in co-op or internship posts and the number of students assisted by career-guidance services.

- To strengthen the development of innovation skills, use review processes within provincial quality-assurance frameworks to ensure that: i) programmes in science, technology, engineering and mathematics fully integrate elements of communication, business and entrepreneurial training; and ii) student-assessment practices evaluate students on higher-order thinking skills and not just knowledge of content.

\section{Bibliography}

Admuti-Trache, M. (2006), "The Labour Market Value of Liberal Arts and Applied Education Programs: Evidence from British Columbia", Canadian Journal of Higher Education, Vol. 36, No. 2.

Advisory Panel on Labour Market Information (2009), "Working Together to Build a Better Labour Market Information System for Canada", Final Report, 20 May. 
Altbach, P., L. Reisberg, M. Yudkevich, G. Androushchak and I. Pacheco (eds.) (2012), Paying the Professoriate: A Global Comparison of Compensation and Contracts, Routledge, London.

AUCC (2011), Trends in Higher Education: Volume 1 - Enrolment, Association of Universities and Colleges of Canada, Ottawa.

Auriol, L. (2010), "Careers of Doctorate Holders: Employment and Mobility Patterns", OECD Science, Technology and Industry Working Papers, No. 2010/04.

Axelrod, P. (2002), Values in Conflict: The University, the Marketplace, and the Trials of Liberal Education, McGill-Queen's University Press, Montreal.

Barro, R.J., G. Mankiw and X. Sala-i-Martin (1995), "Capital Mobility in Neoclassical Models of Growth", American Economic Review, Vol. 85, No. 1.

Berger, J., A. Motte and A. Parkin (eds.) (2009), The Price of Knowledge: Access and Student Finance in Canada, Fourth edition, Canadian Millennium Scholarship Fund, Montreal.

Bonikowska, A., F. Hou, and G. Picot (2011), "Do Highly-educated Immigrants Perform Differently in the Canadian and U.S. Labour Markets?", Statistics Canada, Analytical Studies Research Paper, No. 329.

Boudarbat, B. (2004), "Field of Study Choice by Community College Students in Canada", Economics of Education Review, Vol. 27.

Boudarbat, B. and V. Chernoff (2009), "The Determinants of Education-Job Match Among Canadian University Graduates", IZA Discussion Paper, No. 4513, Institute for the Study of Labor, Bonn.

Carmichael, L. and R. Finnie (2008), "Grants for Students: Equal Access to Postsecondary Education Requires More Than a Student Loan Program”, MESA Project Research Paper, Toronto.

CAUT (2011), CAUT Almanac of Post-Secondary Education in Canada, 2011-2012, Canadian Association of University Teachers, Ottawa.

Cheung, C. and Y. Guillemette (2012), "Tertiary Education: Developing Skills for Innovation and Long-term Growth", OECD Economics Department Working Paper, forthcoming.

CCL (Canadian Council on Learning) (2009), Post-secondary Education in Canada: Meeting our Needs?, February.

Circum Network and R.A. Malatest (2009), Evaluation of the Tri-Agency Indirect Costs Program, Final report prepared for the Interagency Evaluation Steering Committee, Social Sciences and Humanities Research Council, Ottawa.

Clark, I., G. Moran, M.L. Skolnik and D. Trick (2009), Academic Transformation: The Forces Reshaping Higher Education in Ontario, McGill-Queen's University Press, Kingston, Ontario.

CMEC (2011), "Bringing Education in Canada to the World, Bringing the World to Canada: An International Education Marketing Action Plan for Provinces and Territories", A response to the Council of the Federation from Provincial and Territorial Ministers of Education and Immigration, June. 
Coelli, M. (2005), "Tuition, Rationing and Inequality in Post-Secondary Education Attendance", University of British Columbia Working Paper.

Comité Consultatif sur l'Accessibilité Financière aux Études (2011), "Hausses des droits de scolarité et modifications à l'aide financière aux études 2012-13 à 2016-17", Avis à la Ministre de l'Éducation, du Loisir et du Sport, September.

Corak, M., G. Lipps and J. Zhao (2003), "Family Income and Participation in Post-Secondary Education", Statistics Canada, Analytical Studies Research Paper, No. 210.

Coulombe, S. and J.-F. Tremblay (2007), "Skills, Education, and Canadian Provincial Disparity", Journal of Regional Science, Vol. 47, No. 5.

Council of Canadian Academies (2009), Innovation and Business Strategy: Why Canada Falls Short, Report of the Expert Panel on Business Innovation, Ottawa.

Crocker, R. and A. Usher (2006), “Innovation and Differentiation in Canada's Post-secondary Institutions", Canadian Policy Research Networks Research Report, No. 33.

Drewes, T. (2010), "Post-Secondary Education and the Labour Market in Ontario", Higher Education Quality Council of Ontario, Research Paper, 2010.

Educational Policy Institute (2009), "Examination of the Impact of the Provincial Needs Assessment Process for Student Financial Assistance", Report prepared for Council of Ministers of Education, Canada.

Emery, H., A. Ferrer and D. Green (2011), "Long-Term Consequences of Natural Resource Booms for Human Capital Accumulation”, Canadian Labour Market and Skills Researcher Network Working Paper, No. 74.

Farr, M. (2008), "For Teaching-only Faculty, a Controversial Role", http://www.universityaffairs.ca/thosewho-can-teach.aspx.

Finances Québec (2011), “A Fair and Balanced University Funding Plan”, Gouvernement de Québec, Québec.

Finnie, R. and R. Mueller (2008), "The Effects of Family Income, Parental Education and Other Background Factors on Access to Post-Secondary Education in Canada", MESA Project Research Paper, Toronto.

Finnie, R. and A. Usher (2005), "Measuring the Quality of Post-Secondary Education: Concepts, Current Practices and a Strategic Plan", Canadian Policy Research Networks Research Report, No. 28.

Finnie, R., S. Childs, and T. Qiu (2012), "Patterns of Persistence in Postsecondary Education: New Evidence for Ontario", Toronto: Higher Education Quality Council of Ontario.

Giles, P. and T. Drewes (2001), "Liberal Arts Degrees and the Labour Market", Perspectives, Statistics Canada. Catalogue No. 75-001-XPE.

Gunderson, M. and H. Krashinsky (2009), "Do Education Decisions Respond to Returns by Field of Study?", Canadian Labour Market and Skills Researcher Network Working Paper, No. 47. 
HRSDC (2008), “Looking Ahead: A 10-Year Outlook for the Canadian Labour Market (2008-2017)”, Human Resources and Social Development Canada, Ottawa.

IPFSRD (Independent Panel on Federal Support to R\&D) (2011), Innovation Canada: A Call to Action, Ottawa.

Information and Communications Technology Council (2008), Outlook for Human Resources in the Information and Communications Technology Labour Market, 2008 to 2015, October.

Institute for Competitiveness and Prosperity (2009), "Management matters", Working Paper, No. 12, March.

Johnson, D. (2008) "Interprovincial Variation in University Tuition and the Decision to Attend University Immediately after High School Graduation”, MESA Project Research Paper, No. 2008-4, Toronto.

Junor, S. and A. Usher (2004), The Price of Knowledge 2004: Access and Student Finance in Canada, The Canadian Millennium Scholarship Foundation, Montreal.

Lavoie, M. and R. Finnie (1999), "Is it Worth Doing a Science and Technology Degree in Canada?", Canadian Public Policy, Vol. 25, No. 1.

Leuven, E. and H. Oosterbeek (2011), "Overeducation and Mismatch in the Labor Market", in E. Hanushek, S. Machin and L. Woessmann (eds.), Handbook of The Economics of Education, Volume 4, Elsevier, Amsterdam.

Looney, J.W. (2009), “Assessment and Innovation in Education”, OECD Education Working Paper, No. 24.

McElroy, L. (2004), The Millennium Bursary in B.C.: Exploring its Impact, Canada Millennium Scholarship Foundation, Montreal.

Morissette, R., Y. Ostrovsky and G. Picot (2004), "Relative Wage Patterns among the Highly Educated in a Knowledge-Based Economy”, Statistics Canada, Analytical Studies Branch Research Paper, No. 32 .

OCUFA (2008), "Career limiting move? Teaching-only Positions in Ontario Universities", Ontario Confederation of University Faculty Associations Policy Background Paper. Toronto.

OECD (2005), “E-learning in Tertiary Education: Where Do We Stand?”, Policy Brief.

OECD (2006), Live Longer, Work Longer, OECD Publishing.

OECD (2010a), Pathways to Success: How Knowledge and Skills at Age 15 Shape Future Lives in Canada, OECD Publishing.

OECD (2010b), The OECD Innovation Strategy, OECD Publishing.

OECD (2011a), Education at a Glance, OECD Publishing.

OECD (2011b), Skills for Innovation and Research, OECD Publishing.

OECD (2011c), Science, Technology and Industry Scoreboard 2011, OECD Publishing. 
OECD (2011d), Towards an OECD Skills Strategy, OECD Publishing.

OECD (2012), OECD Economic Surveys: Canada, OECD Publishing.

Pakravan, P. (2006), "The Future is Not What it Used to Be: Re-examining Provincial Post-secondary Funding Mechanisms in Canada", C.D. Howe Institute Education Papers, No. 227.

Palameta, B. and J-P. Voyer (2010), "Willingness to Pay for Post-secondary Education among Under-represented Groups - Report", Higher Education Quality Council of Ontario, Toronto.

Pyper, W. (2008), “Skilled Trades Employment”, Perspectives, Statistics Canada, Cat. No. 75-001-X, February.

Psacharopoulos, G. (2008), "Funding Universities for Efficiency and Equity: Research Findings versus Petty Politics", Education Economics, Vol. 16, No. 3.

Quintini, G. (2011), “Over-Qualified or Under-Skilled: a Review of Existing Literature”, OECD Social, Employment and Migration Working Paper No. 121, Paris.

Riddell, W.C. (2001), "Education and Skills: An Assessment of Recent Canadian Experience", in: P. Grady and A. Sharpe (eds.), The State of Economics in Canada: Festschrift in Honour of David Slater, Centre for the Study of Living Standards, Ottawa.

Rollin, A-M. (2011), "The Income of Immigrants Who Pursue Postsecondary Education in Canada", Perspectives on Labour and Income, Statistics Canada.

Santiago, P., K. Tremblay, E. Basri and E. Arnal (2008), Tertiary Education for the Knowledge Society: Volume 1 and Volume 2, OECD Publishing.

Sharpe, A. (2005), “What Explains the Canada-US ICT Investment Intensity Gap?”, International Productivity Monitor, No. 11, Fall.

Skolnik, M. (2004), "The Relationship of the Community College to Other Providers of Postsecondary and Adult Education in Canada and Implications for Policy", Higher Education Perspectives, Vol. 1, Issue 1.

Stark, A. (2007), “Which Fields Pay, Which Fields Don't? An Examination of the Returns to University Education in Canada by Detailed Field of Study", Department of Finance Canada, Economic Studies and Policy Analysis Division, February.

Statistics Canada (2009), "College and University Graduates With Low Earnings in Canada Demographic and Labour Market Characteristics", Education Matters: Insights on Education, Learning and Training in Canada, Vol. 6, No. 2.

Snowdon, K. (2005), "Without a Roadmap: Government Funding and Regulation of Canada's Universities and Colleges", Canadian Policy Research Networks Research Report, No. 31.

Sweetman, A. and C. Warman (2009), "Temporary Foreign Workers and Former International Students as a Source of Permanent Immigration", Canadian Labour Market and Skills Researcher Network Working Paper, No. 25. 
Trottier, C. and J. Bernatchez (2005), "Higher Education Policy in Québec: A Case Study", Alliance for International Higher Education Policy Studies.

UNESCO (2011), Global Education Digest 2011: Comparing Education Statistics Across the World, United Nations Educational, Scientific and Cultural Organization Institute for Statistics, Paris.

Usher, A. and P. Duncan (2008), Beyond the Sticker Shock 2008: A Closer Look at Canadian Tuition Fees, Educational Policy Institute, Toronto.

Vajoczki, S., N. Fenton, K. Menard and D. Pollon (2011), “Teaching-Stream Faculty in Ontario Universities", Higher Education Quality Council of Ontario, Toronto.

Vandenbussche, J., P. Aghion and C. Meghir (2006), "Growth, Distance to Frontier and Composition of Human Capital”, Journal of Economic Growth, Vol. 11, No. 2.

Walters, D. and K. Frank (2010), "Exploring the Alignment Between Postsecondary Education Programs and Labour Market Outcomes in Ontario", Higher Education Quality Council of Ontario, Toronto.

Yuen, J. (2010), “Job-Education Match and Mismatch: Wage Differentials", Statistics Canada, April,Perspectives, Catalogue No. 75-001-X, Ottawa. 
ECO/WKP(2012)68

\section{Annex}

\section{Multifactor productivity by province accounting for sectoral composition}

To explore the factors behind provincial variations in productivity while accounting for differences in industrial composition, a general production function is assumed with the conventional Cobb-Douglas functional form:

$$
y=A k^{\alpha}
$$

where $y$ is labour productivity, $k$ is the ratio of capital to labour input (i.e. capital intensity) and $\alpha$ determines the degree of concavity of the production function. The multiplicative term $A$, which is commonly referred to as multifactor productivity, is a measure of the variation in output per unit of combined inputs.

Using Statistics Canada's System of National Accounts, estimates of labour productivity by province, industry (NAICS 2-digit) and year (1997 to 2010) are obtained by dividing GDP at basic prices by total hours worked (Table A.1). This exercise yields 2520 observations on labour productivity at a disaggregated level across 10 provinces, 18 industries and 14 years.

Table A.1. Average labour productivity by province and industry, 1997-2010

Value-added per hour worked (CAD 2002)

\begin{tabular}{|c|c|c|c|c|c|c|c|c|c|c|}
\hline & NL & PE & NS & NB & QC & ON & MB & SK & $A B$ & BC \\
\hline Agriculture, forestry, fishing and hunting & 36.8 & 26.2 & 23.5 & 26.6 & 29.0 & 23.3 & 24.6 & 34.7 & 35.1 & 35.3 \\
\hline Mining and oil and gas extraction & 339.2 & 43.5 & 120.6 & 42.5 & 43.7 & 64.3 & 72.0 & 183.8 & 162.7 & 134.1 \\
\hline Utilities & 114.2 & 90.7 & 124.2 & 128.2 & 186.6 & 106.6 & 135.0 & 153.0 & 182.0 & 181.7 \\
\hline Construction & 25.1 & 16.1 & 22.6 & 21.8 & 32.9 & 28.3 & 23.6 & 29.3 & 29.8 & 26.6 \\
\hline Manufacturing & 25.9 & 31.6 & 33.7 & 35.7 & 44.0 & 51.1 & 35.7 & 46.5 & 53.2 & 41.7 \\
\hline Wholesale trade & 33.7 & 28.1 & 32.3 & 37.4 & 33.2 & 37.0 & 42.0 & 47.8 & 40.9 & 32.3 \\
\hline Transportation and warehousing & 23.4 & 19.7 & 26.3 & 27.1 & 31.0 & 32.9 & 32.7 & 39.4 & 40.9 & 37.7 \\
\hline Information and cultural industries & 58.7 & 71.9 & 56.2 & 58.8 & 56.1 & 56.4 & 58.2 & 53.0 & 66.2 & 55.4 \\
\hline $\begin{array}{l}\text { Finance and insurance, real estate and } \\
\text { renting }\end{array}$ & 141.7 & 138.4 & 132.9 & 128.2 & 108.2 & 114.3 & 120.1 & 119.3 & 126.7 & 134.3 \\
\hline $\begin{array}{l}\text { Professional, scientific and technical } \\
\text { services }\end{array}$ & 24.1 & 23.6 & 25.1 & 26.8 & 29.4 & 31.5 & 24.1 & 25.6 & 33.0 & 28.4 \\
\hline $\begin{array}{l}\text { Administrative and support, waste } \\
\text { management }\end{array}$ & 18.2 & 14.4 & 17.1 & 14.8 & 21.1 & 22.5 & 18.3 & 18.5 & 24.8 & 19.0 \\
\hline Arts, entertainment and recreation & 15.1 & 14.7 & 15.5 & 18.0 & 23.6 & 22.8 & 18.6 & 20.5 & 18.2 & 20.5 \\
\hline Accommodation and food services & 12.9 & 13.2 & 12.8 & 12.4 & 14.4 & 14.7 & 13.5 & 13.3 & 16.5 & 15.5 \\
\hline Other services (except public administration) & 13.6 & 13.7 & 13.6 & 13.6 & 17.4 & 18.9 & 16.3 & 16.9 & 19.8 & 18.1 \\
\hline Public administration & 43.3 & 42.6 & 39.3 & 39.9 & 46.2 & 46.3 & 41.4 & 37.0 & 45.8 & 53.0 \\
\hline Average aggregate labour productivity & 40.5 & 29.1 & 31.7 & 31.2 & 37.4 & 40.3 & 33.7 & 39.2 & 46.4 & 37.9 \\
\hline
\end{tabular}

Source: Statistics Canada, CANSIM Tables 379-0025 and 383-0009.

Under the standard microeconomic assumptions of perfect competition in output and input markets and with constant returns to scale, $\alpha$ equals the marginal productivity of physical capital and also corresponds to the share of total income allocated to capital. Estimates of this share are obtained by subtracting estimates of the share of total income allocated to labour from one. Estimates of the share of total income allocated to labour are in turn obtained by dividing total compensation for all jobs (based on 
data obtained from CANSIM Table 383-0009) by GDP at the same level of disaggregation as for labour productivity. Estimates of $\alpha$ hover around an average share of 0.4 depending on the industry, province and year. Given that disaggregated data on compensation are available only until 2008, capital share estimates in 2009 and 2010 are assumed to remain at their estimated values for 2008 .

Measures of capital intensity are obtained by dividing fixed non-residential capital by hours worked at the same level of disaggregation as for labour productivity (Table A.2). Because of confidentiality issues, capital stock estimates are not available for certain industries in some provinces. Multifactor productivity levels for each province, industry and year are then calculated as residuals using the Cobb-Douglas production function presented above (Table A.3).

Table A.2. Average capital intensity, 1997-2010

Fixed non-residential capital per hour worked (CAD 2002)

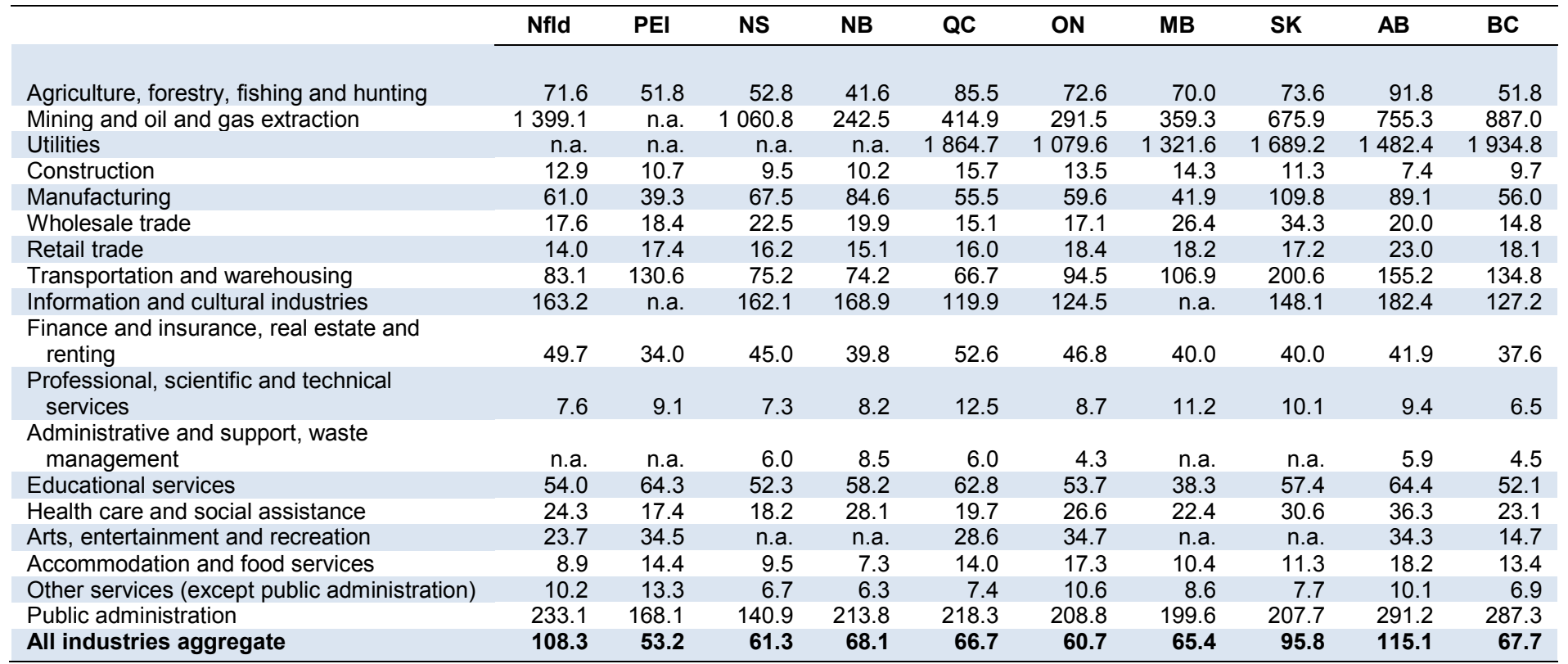

Note: n.a. is undisclosed for confidentiality purposes. Capital stock is fixed non-residential capital - all components, which includes building construction, engineering construction and machinery and equipment.

Source: Statistics Canada, CANSIM Table 031-0002.

The results show that for the period considered, average aggregate multifactor productivity levels vary substantially from a minimum in Saskatchewan to a maximum in Ontario. Such large differences across provinces, however, not only stem from productivity differences at the industry level, but also from disparities in industrial composition across provinces. Indeed, a province that has a larger share of employment in high productivity industries will tend to have a higher overall average productivity level, despite having the same productivity levels on an industry-by-industry basis as another province. The extent to which aggregate productivity level differences across provinces originate from differences in industrial structures or from a general productivity advantage in most or in all industries is therefore not clear. Interprovincial differences in productivity performance may therefore be explained by quantifying the relative importance of industrial structure versus "real" productivity performance. This may be accomplished through a regression of estimated multifactor productivity levels on indicator variables. The estimating equation used for this purpose is:

$$
M F P_{p, i, t}=\beta_{0}+\beta_{p} P_{p}+\gamma_{i} I_{i}+\delta_{t} T_{t}+\varepsilon_{p, i, t}
$$


where $M F P_{p, i, t}$ is value-added per hour worked in province $p$, industry $i$ and year $t$. The $I_{i}$ are indicator variables for industries so their estimated coefficients $\left(\gamma_{i}\right)$ are shift factors capturing industry fixed-effects. These capture natural differences in productivity levels across industries common to all provinces and years. Similarly, the $T_{t}$ are indicator variables for years so their coefficients $\left(\delta_{t}\right)$ capture the general increase in productivity levels through time as well as cyclical economic effects common to all industries and provinces. The $P_{p}$ are indicator variables for provinces and their estimated coefficients $\left(\beta_{p}\right)$ capture province-specific differences in multifactor productivity. These coefficients can be interpreted as average multifactor productivity levels over the period 1997 to 2010 after accounting for differences in sectoral composition across provinces as these are absorbed by the industry fixed effects. Given that the province of Ontario, the manufacturing industry and the year 1997 are the excluded categories, the constant $\left(\beta_{0}\right)$ can roughly be interpreted as the multifactor productivity level in manufacturing in Ontario in 1997. Finally, $\varepsilon_{p, i, t}$ is an error term. Because influences on MFP levels specific to a given province and sector persist through time, observations for province-sector pairs cannot be treated as statistically independent across years. Observations have therefore been grouped into province-sector clusters, and robust standard errors have been calculated using the Huber-White sandwich estimator.

Table A.3. Average multifactor productivity by province and industry, 1997-2010

\begin{tabular}{|c|c|c|c|c|c|c|c|c|c|c|}
\hline & NFLD & PEI & NS & NB & QC & ON & MB & SK & $A B$ & BC \\
\hline Agriculture, forestry, fishing and hunting & 2.98 & 2.79 & 4.52 & 5.65 & 2.61 & 2.29 & 1.16 & 1.14 & 1.52 & 7.45 \\
\hline Mining and oil and gas extraction & 0.91 & n.a. & 0.78 & 2.77 & 2.98 & 2.29 & 2.11 & 0.70 & 0.84 & 0.74 \\
\hline Utilities & n.a. & n.a. & n.a. & n.a. & 0.49 & 1.00 & 0.80 & 0.60 & 0.59 & 0.49 \\
\hline Construction & 11.00 & 11.12 & 15.48 & 13.45 & 15.11 & 16.56 & 13.26 & 12.76 & 20.64 & 16.76 \\
\hline Manufacturing & 7.95 & 6.45 & 7.85 & 4.92 & 7.60 & 9.79 & 6.88 & 4.72 & 6.77 & 9.87 \\
\hline Wholesale trade & 8.70 & 9.84 & 10.03 & 9.20 & 13.46 & 14.92 & 8.72 & 6.36 & 14.88 & 15.58 \\
\hline Retail trade & 7.52 & 7.42 & 8.50 & 8.21 & 9.17 & 9.78 & 8.45 & 8.77 & 10.25 & 10.84 \\
\hline Transportation and warehousing & 8.69 & 4.54 & 8.85 & 8.08 & 8.64 & 8.24 & 7.05 & 2.77 & 5.12 & 7.88 \\
\hline Information and cultural industries & 3.75 & n.a. & 2.86 & 4.42 & 5.86 & 5.80 & N/A & 5.70 & 3.25 & 4.77 \\
\hline $\begin{array}{l}\text { Finance and insurance, real estate and } \\
\text { renting }\end{array}$ & 5.95 & 8.46 & 6.44 & 7.25 & 6.21 & 7.72 & 7.86 & 7.34 & 8.41 & 8.63 \\
\hline $\begin{array}{l}\text { Professional, scientific and technical } \\
\text { services }\end{array}$ & 17.49 & 14.51 & 16.18 & 18.36 & 16.68 & 22.02 & 15.37 & 15.82 & 21.19 & 21.33 \\
\hline Administrative and support, waste & & & & & & & & & & \\
\hline management & n.a. & n.a. & 11.94 & 10.55 & 13.38 & 16.18 & N/A & N/A & 16.98 & 14.84 \\
\hline Educational services & 26.23 & 24.71 & 24.69 & 21.83 & 24.35 & 26.54 & 20.58 & 22.54 & 25.64 & 22.95 \\
\hline Health care and social assistance & 17.78 & 19.20 & 15.87 & 17.05 & 15.54 & 17.11 & 14.17 & 13.61 & 15.38 & 17.26 \\
\hline Arts, entertainment and recreation & 7.56 & 5.11 & n.a. & n.a. & 8.70 & 10.44 & n.a. & n.a. & 9.15 & 11.94 \\
\hline Accommodation and food services & 7.88 & 6.09 & 7.58 & 7.72 & 8.38 & 8.22 & 7.81 & 7.18 & 7.52 & 9.24 \\
\hline Other services (except public administration) & 9.12 & 8.38 & 9.65 & 9.95 & 11.40 & 12.95 & 11.79 & 12.01 & 12.98 & 13.95 \\
\hline Public administration & 8.74 & 14.00 & 15.80 & 9.83 & 10.61 & 12.98 & 11.11 & 9.52 & 9.50 & 12.28 \\
\hline $\begin{array}{l}\text { Average aggregate multifactor } \\
\text { productivity }\end{array}$ & 3.28 & 6.20 & 6.26 & 5.92 & 6.75 & 8.15 & 5.60 & 3.13 & 4.07 & 6.86 \\
\hline
\end{tabular}

Source: OECD calculations.

Coefficient estimates and robust standard errors for the province indicators are reported in Table $4{ }^{8}$ Again, because Ontario is omitted, the coefficient estimates must be interpreted as MFP gaps relative to Ontario. These are all statistically significant at the 1\% level, except for Alberta and British Columbia. This suggests that these two provinces have MFP levels that are statistically indistinguishable from Ontario's after accounting for differences in industrial structures. Other provinces, however, all have statistically significant negative gaps relative to Ontario. Compared to the estimated average level of MFP for Ontario over this period, they signify that, all else equal (i.e. under identical conditions for capital intensity, industrial structure and number of hours worked), living standards in these provinces would be anywhere between $60 \%$ and $80 \%$ of Ontario's average living standard.

8. Most sector and year dummy variables are statistically significant at the $5 \%$ level but they are not reported. 
Table A.4. Estimated provincial MFP gaps relative to Ontario

\begin{tabular}{lcccccccc}
\hline NfId & PEI & NS & NB & QC & MB & SK & AB & BC \\
\hline$-2.233^{*}$ & $-2.599^{*}$ & $-1.622^{*}$ & $-2.109^{*}$ & $-1.315^{*}$ & $-2.460^{*}$ & $-3.026^{*}$ & -0.789 & 0.110 \\
$(0.50)$ & $(0.63)$ & $(0.49)$ & $(0.47)$ & $(0.37)$ & $(0.45)$ & $(0.51)$ & $(.59)$ & $(.47)$ \\
\hline $\begin{array}{l}\text { Summary statistics } \\
\text { R-squared }\end{array}$ & 0.9058 & F-value (39, 164) & 89.07 & Wald p-value & 0.0000 \\
Observations & 2310 & Prob > F & 0.0000 & \# of clusters & 165 \\
\hline
\end{tabular}

Note: Huber-White robust standard errors are in parentheses. *Significant at $1 \%$ level. The Wald statistics is used to test that all provincial MFP gaps are zero. Estimated coefficients for sector and year dummies are not reported.

\section{What could explain such large discrepancies?}

One factor known to enter the production function is the quality of labour input. This factor was not included in the production function directly, however, given that data are not available at this level of disaggregation. Even if data were available, the quality of labour input constitutes a parameter that is difficult to measure: only indirect proxies are available. The most common proxy used is the educational attainment of the workforce measured in average years of schooling. In light of the fact that primary and secondary education in Canada is widely available, largely compulsory and of generally good quality, the most notable differences in levels of educational attainment across provinces are seen at the tertiary education level. Such differences across provinces are particularly important, given that innovation and productivity performance are largely dependent on the extent of tertiary education acquired by individuals. Hence, the provincial MFP gaps with Ontario might be explained to some extent by such human capital variations. The measure used here is the share of the population 15 years of age and over with a minimum of a bachelors degree. In 2010, this share ranged from 12\% in Newfoundland and Labrador to $23.5 \%$ in Ontario. Averages for these shares were calculated over the same time period used to derive MFP measures (i.e. 1997 to 2010), and gaps with Ontario were computed by subtracting Ontario's average share. Although the relationship is based on only 10 data points, the positive correlation between higher education attainment and multifactor productivity (Figure A.1) suggests that if Saskatchewan, for example, clawed back its 7 percentage point tertiary education attainment gap with Ontario, it might reduce its composition-adjusted MFP gap with Ontario by three quarters.

Figure A.1. Productivity and university attainment across provinces

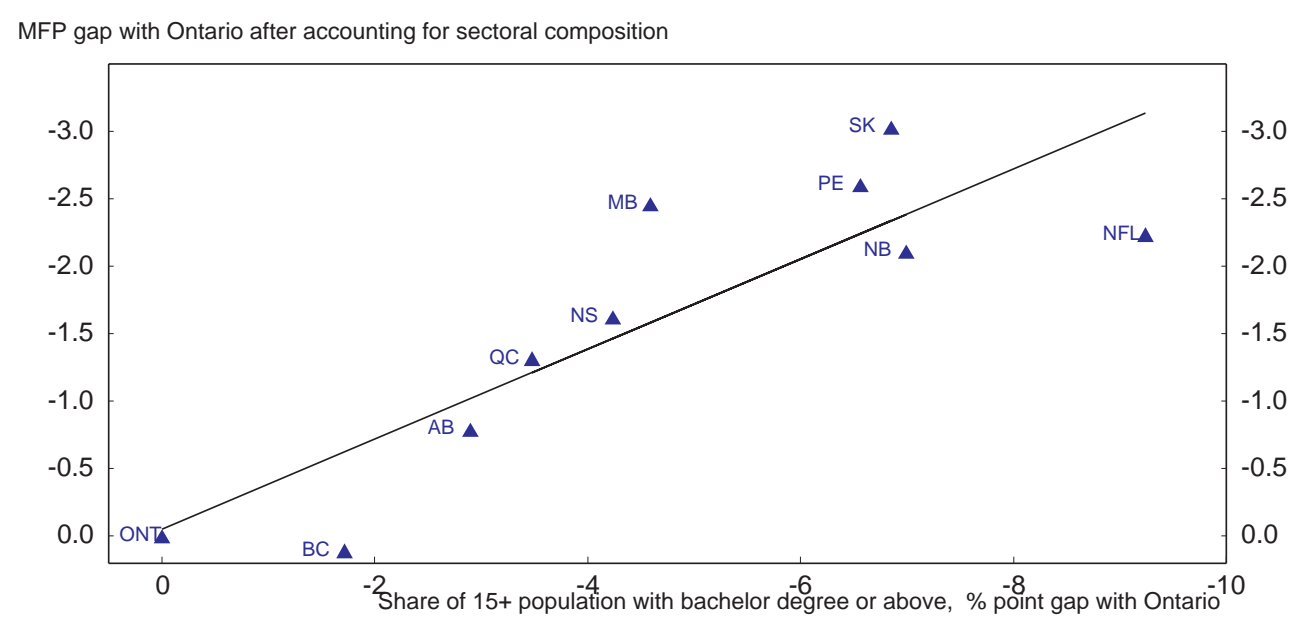

Source: OECD calculations. 


\section{WORKING PAPERS}

The full series of Economics Department Working Papers can be consulted at www.oecd.org/eco/workingpapers/

990. Trade and product market policies in upstream sectors and productivity in downstream sectors: firm-level evidence from China

(September 2012) by Maria Bas and Orsetta Causa

989. Intangible assets, resource allocation and growth: a framework for analysis

(September 2012) by Dan Andrews and Alain de Serres

988. Current account benchmarks for Turkey

(September 2012) by Oliver Röhn

987. Structural reforms to boost Turkey's long-term growth

(September 2012) by Rauf Gönenç, Oliver Röhn, Vincent Koen and Şeref Saygili

986. Tackling Turkey's external and domestic macroeconomic imbalances

(September 2012) by Oliver Röhn, Rauf Gönenç, Vincent Koen and Ramazan Karaşahin

985. Portugal: Solid foundations for a sustainable fiscal consolidation

(September 2012) by David Haugh and Stéphane Sorbe

984. Portugal: Assessing the risks around the speed of fiscal consolidation in an uncertain environment

(September 2012) by Stéphane Sorbe

983. The German labour market: preparing for the future

(September 2012) by Felix Hüfner and Caroline Klein

982. Climate change policies in Germany: make ambition pay

(September 2012) by Caroline Klein

981. Restarting the growth engine in Finland

(September 2012) by Henrik Braconier

980. Import Competition, Domestic Regulation and Firm-Level Productivity Growth in the OECD (September 2012) by Sarra Ben Yahmed and Sean Dougherty

979. Non-Parametric Stochastic Simulations to Investigate Uncertainty around the OECD Indicator Model Forecasts

(August 2012) by Elena Rusticelli

978. $\quad$ Measuring GDP Forecast Uncertainty using Quantile Regressions

(July 2012) by Thomas Laurent and Tomasz Kozluk

977. Implications of output gap uncertainty in times of crisis

(July 2012) by Romain Bouis, Boris Cournède and Ane Kathrine Christensen 
976. Avoiding debt traps: financial backstops and structural reforms

(July 2012) by Pier Carlo Padoan, Urban Sila and Paul van den Noord

975. Sluggish productivity growth in Denmark: the usual suspects?

(July 2012) by Müge Adalet McGowan and Stéphanie Jamet

974. Towards green growth in Denmark: improving energy and climate change policies (July 2012) by Stéphanie Jamet

973. An Analysis of Productivity Performance in Spain before and during the Crisis: Exploring the Role of Institutions

(June 2012) Juan S. Mora-Sanguinetti and Andrés Fuentes

972. Europe's new fiscal rules

(June 2012) by Sebastian Barnes, David Davidsson and Łukasz Rawdanowicz

971. Credit Crises and the Shortcomings of Traditional Policy Responses

(June 2012) by William R. White

970. International Capital Mobility and Financial Fragility

Part 7. Enhancing Financial Stability: Country-specific Evidence on Financial Account and

Structural Policy Positions

(June 2012) by Rudiger Ahrend and Carla Valdivia

969. International Capital Mobility and Financial Fragility

Part 6. Are all Forms of Financial Integration Equally Risky in Times of Financial Turmoil? Asset Price Contagion during the Global Financial Crisis

(June 2012) by Rudiger Ahrend and Antoine Goujard

968. International Capital Mobility and Financial Fragility

Part 5. Do Investors Disproportionately Shed Assets of Distant Countries under Increased

Uncertainty? Evidence from the Global Financial Crisis

(June 2012) by Rudiger Ahrend and Cyrille Schwellnus

967. International Capital Mobility and Financial Fragility

Part 4. Which Structural Policies Stabilise Capital Flows when Investors Suddenly Change their

Mind? Evidence from Bilateral Bank Data

(June 2012) by Rudiger Ahrend and Cyrille Schwellnus

966. International Capital Mobility and Financial Fragility

Part 3. How do Structural Policies affect Financial Crisis Risk? Evidence from Past Crises across $O E C D$ and Emerging Economies

(June 2012) by Rudiger Ahrend and Antoine Goujard

965. Sustaining Korea's convergence to the highest-income countries

(June 2012) by Randall S. Jones and Satoshi Urasawa

964. Achieving the "low carbon, green growth" vision in Korea

(June 2012) by Randall S. Jones and Byungseo Yoo 